\title{
Guillem Carabí
}

\section{L'ÀNGEL PENELL QUE CORONA LA CASA BOFARULL: ALGUNES CONSIDERACIONS A L'ENTORN DE L'ESCULTURA}

\author{
Angele Dei qui custos es mei; me tibi \\ commissum pietate superna, hodie illumina, \\ custodi, rege et guberna. \\ Amen.
}

Pregària del segle XII atribuïda a sant Anselm
Durant quasi dues dècades i amb dilatades interrupcions, I'arquitecte Josep M. Jujol (Tarragona 1879 - Barcelona 1949) dibuixarà i dirigirà les obres de reforma d'una vella masia originària del segle xvi: la Casa Bofarull. Situada al poble dels Pallaresos del Camp de Tarragona, serà objecte d'un seguit de transformacions per ennoblir-la, des de finals de I'any 1913 fins al 1933. D'entre totes les intervencions volem subratllar la figura que corona el punt més alt: un àngel penell sobre la coberta de l'escala mirador que assenyala la direcció dels vents i reïfical I'edifici de la família Bofarull. L'àngel, de més de $400 \mathrm{~kg}$ de pes i amb unes solucions plàstiques poc habituals en la tradició d'àngels penell de l'època, es configura com una peça cabdal l'estudi de la qual orienta la comprensió dels processos creatius de I'arquitecte Jujol. Analitzar i interpretar I'àngel penell de la Casa Bofarull és I'objecte d'aquest article.

La primera imatge que obtenim del terme, quan ens acostem al nucli del municipi, no és gaire habitual: a la visió Ilunyana i elevada del campanar de I'església parroquial de Sant Salvador se li afegeix, a pocs metres de distància, la figura alada que remata la coberta de la Casa Bofarull (fig. 1). La topografia del lloc juga a favor d'un o de I'altra segons sigui la posició de I'observador: àngel i campanar semblen competir per I'hegemonia d'una alçada que, tradicionalment, es reservava al campanar de l'església. No obstant això, una hipotètica disputa per ostentar la major alçada no sembla versemblant en tant que les propietàries de la Casa Bofarull, les ger-
${ }^{1}$ Fer real allò que no ho és; traslladar el món diví a la terra. 


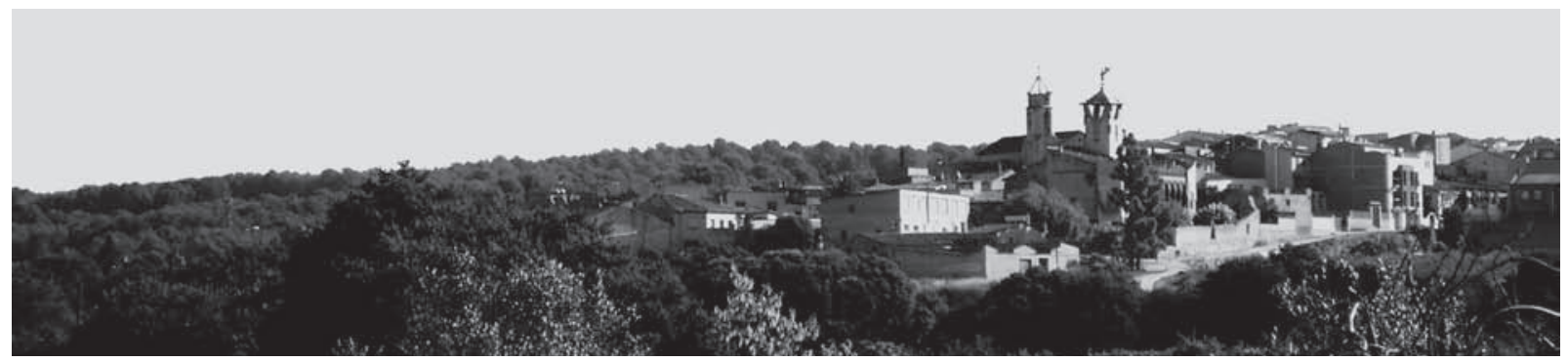

1. Visió actual de l'agulla del campanar de l'església de Sant Salvador i de l'àngel penell de la Casa Bofarull. Fotografia de l'autor.

2 Els Bofarull, juntament amb els Fortuny, són les dues úniques famílies amb avantpassats enterrats sota les pedres de l'església parroquial, fruit de les aportacions econòmiques que van permetre, al segle XVIII, construir I'edifici. manes Dolors i Josepa Bofarull, mantenien amb la parròquia una relació fluida i de constant col·laboració. ${ }^{2}$ Les dues germanes són recordades pels seus actes solidaris envers la població més desatesa; les seves accions aniran des de l'esmorzar setmanal que oferiran a veïns i gent de contrades fins a assumir el cost dels habitatges d'alguns dels operaris que treballaran a les obres de reforma de la masia, o sufragar l'ampliació del vell cementiri quan la seva mida ja no sigui suficient per assolir les necessitats de la comunitat.

La coincidència d'alçades entre ambdós coronaments - església i Casa Bofarull - sembla que es mou més en el terreny d'allò visual. La incidència d'un edifici en el seu entorn urbà depèn, en gran mesura, de la capacitat d'ésser contemplat i reconegut des d'una distància que no superi una visió raonable d'ús: si reconèixer la imatge d'un edifici —o d’una partposa de manifest la capacitat d'esdevenir un signe, no és menys cert que coronar-lo mitjançant una estàtua de clar ordre simbòlic el connota, atorgant-li una dignitat que transcendeix allò més particular per implicar-se en un reconeixement d'ordre públic. La figura de l'àngel (fig. 2) mira i es deixa mirar; esdevé un guia que condueix cap a la casa; I'estàtua, ara transformada en penell, no compleix només una funció representativa i mecànica des de la seva posició privilegiada, sinó que la seva gènesi i la seva materialització segueixen un recorregut en el llenguatge material i formal que la relacionen coherentment amb les operacions que Jujol realitza a la reforma. Més enllà del recurs simbòlic que Jujol explora a les diferents làmines d'estudi de l'àngel, com a solució de coronament de la casa, afloren algunes qüestions sense resoldre molt afins al control perceptiu que Jujol exerceix sobre els elements presents, i que caracteritzaran la seva arquitectura. 


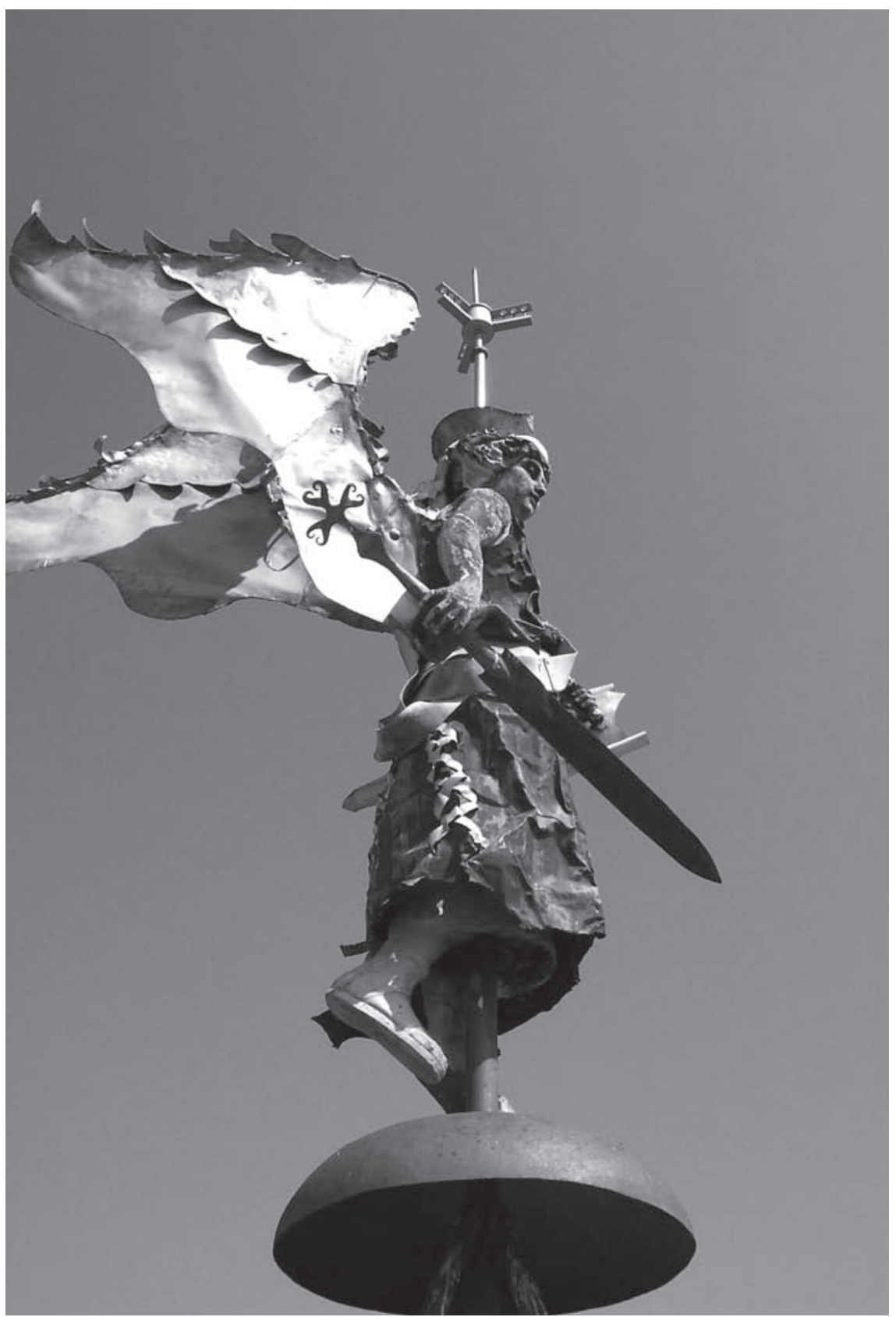

2. Imatge de l'àngel que corona la Casa Bofarull, tal com es restaurà durant l'any 2000 per l'empresa Tallers Salvat. Els treballs van consistir en la restauració de la xapa del vestit, el retorn de les ales al seu estat original, separades durant l'època franquista, i la recuperació del moviment que li permet actuar de penell. L'element que actua de parallamps es va incorporar durant la restauració. Fotografia de l'autor. 
3 El terme plàstic apareix com a adjectiu a Espanya, per primera vegada, al Diccionario castellano d'Esteban Terreros publicat entre 1765 i 1783, com a qualificatiu que ha d'acompanyar sempre la Virtut: «los Filósofos antighuos y algunos Médicos entendieron por virtud plástica aquella con que imajinaron que el alma era la que formaba, ó fabricaba su cuerpo, también entendían que Dios había dado al útero de la hembra, cierta virtud plástica para formar el feto». Esteban de Terreros y Pando, Diccionario castellano con las voces de ciencias y artes, vol. 4, Madrid, imprenta de la vda. de Ibarra, hijos y cía., 17861793, p. 155. Quan faci ús de termes com plasticisme, allò plàstic, els utilitzaré, en endavant, en I'accepció que Theo Van Doesburg assenyala cap al 1917: «Plasticismo es hacer visible una forma o color en relación con el espacio y con otra forma o color». Theo van DOEsBuRg: "Principios del nuevo arte plástico», Principios del nuevo arte plástico y otros escritos, Múrcia, Colegio Oficial de Arquitectos y Aparejadores de Murcia, 1985, p. 32. La base fonamental de la definició de Van Doesburg es troba en I'absència de protagonisme de l'artista respecte a I'obra d'art: I'art plàstic inaugurarà una nova forma de relació entre I'obra i I'espectador, relació que té a veure amb la percepció sensorial a què Jujol apel·larà constantment.

\section{Qüestions preliminars}

El primer assumpte a tractar és el caràcter de la imatge que representa la figura; la presència des del símbol és quelcom difícil d'obviar: I'àngel com a esperit protector. Però I'operació que Jujol du a terme amb la figura alada de la Casa Bofarull no s'atura a la definició iconogràfica; la intervenció suggereix un segon interrogant més afí a temes perceptius i arquitectònics: la posició, les dimensions, el mecanisme i la definició formal obliguen a explorar, a més de l'evident connotació simbòlica, aspectes que remeten a l'univers plàstic ${ }^{3}$ de Jujol i la relació íntima i directa amb l'arquitectura.

Anem, però, a pams i ocupem-nos del primer tema anunciat: I'àngel com a imatge o representació. Per això recordem, breument, els estímuls de la formació universitària del jove Jujol. Durant el període d'estudis a I'Escola d'Arquitectura de Barcelona, Jujol assimila una línia acadèmica - iniciada per Rogent i continuada per Domènech i Montaner - profundament allunyada del classicisme i que accentua la recuperació de la tradició local. La influència directa dels arquitectes que imparteixen docència es veurà reflectida en els exercicis escolars, sobretot pel que fa a la imatge que, de la façana, tindran els seus exercicis. Jujol és alumne d'arquitectes com Gallissà, Font i Gumà - amb els quals col·laborarà professionalment durant els estudis - , Puig i Cadafalch, Artigas Ramoneda, August Font, Torras Guardiola ${ }^{4}$ o Bassegoda Amigó, entre d'altres, sempre en la línia docent establerta per Domènech i Montaner. Al Ilarg dels exercicis proposats, els alumnes, en els programes d'evident caràcter religiós - panteons, esglésies, capelles-, utilitzen el coronament en creu com a solució inherent a l'edifici mateix. Aquesta solució, de fortes reminiscències medievals, es farà extensible a altres programes civils, com per exemple als exercicis Embarcadero en un río para una gran finca de recreo, de l'any 1902, de Pere Domènech i Roure, Proyecto de estación (1909), d'Antoni Darder i Marsà, o I'Establecimiento termal (1905) (fig. 3), del mateix Jujol, per citar-ne alguns. En tots, I'agulla o la creu coronen els punts alts dels seus projectes. Paral-lelament a la pràctica més acadèmica s'ha d'afegir, des de I'any 1906, la col·laboració que Jujol inicia amb Gaudí i la indubtable influència - de caràcter recíproc - que el mestre de Reus hi exercirà. Edificis civils com el Palau Güell (1886-1888), la Casa Calvet (1898-1900), Bellesguard (1900) o les edificacions principals del Park Güell (19001903) (fig. 4), tots de caràcter privat, contenen torres coronades per creus que, amb tota seguretat, havien estat observades en més d'una ocasió per I'arquitecte de la reforma de la Casa Bofarull. ${ }^{5}$ És, per tant, raonable afirmar que I'aproximació de Jujol a una tradició pròpia i coetània ${ }^{6}$ es realitza 


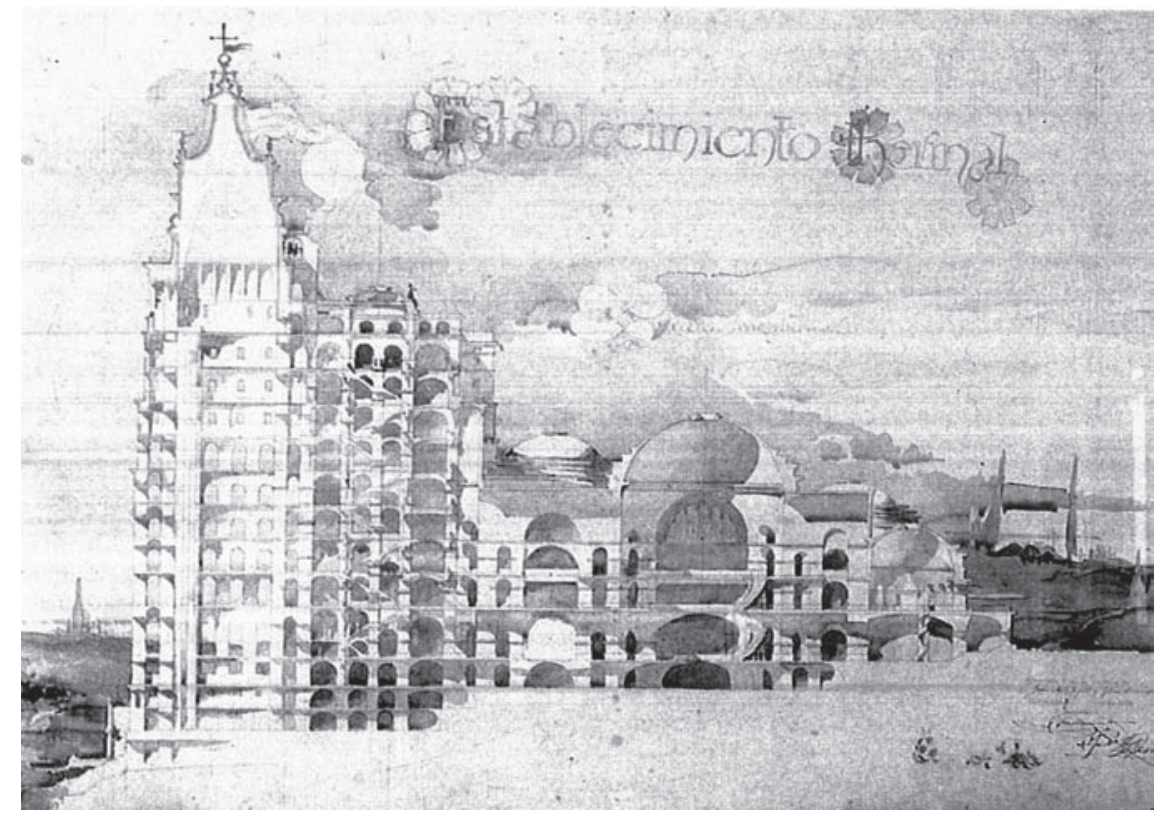

3. Establiment termal, secció. Projecte Final de Carrera de Josep M. Jujol. Imatge extreta d'Antoni Ramon i Carme Rodríguez, Escola d'Arquitectura de Barcelona, Barcelona, UPC, 1996, p. 68.

de manera natural incorporant, a més, un entusiasme religiós l'origen del qual es pot trobar tant al seu entorn familiar ${ }^{7}$ com potenciat, probablement, a través de la mirada compartida d'un Antoni Gaudí amb una tendència espiritualista creixent amb el pas dels anys i a mesura que els treballs a la Sagrada Família esdevenien més i més intensos. ${ }^{8}$

Amb tot aquest bagatge a I'esquena, la proposta figurativa que Jujol dissenya per coronar la Casa Bofarull des de les alçades, respon tant a una pràctica arquitectònica de coronació habitual en els anys i I'entorn en què es desenvolupa com a un desig personal de fer evident un especial fervor religiós. Però si I'ús o la incorporació del coronament vertical de l'edifici pot trobar resposta en una manera de fer pròpia del seu temps, la concreció en una icona determinada - reconèixer en la figura un àngel custodi o un arcàngel - ha estat una de les discussions més recurrents per part dels autors que s'han referit a la figura alada. La discussió no és estèril: en la interpretació que Jujol realitza de la figura poden llegir-se la postura que adoptarà amb la tradició i les conseqüències que porta implícites la incorporació simbòlica relacionada de manera específica amb un entorn i unes característiques historicotopogràfiques pròpies del Iloc. 0 , dit d'una altra manera: com Jujol pot transgredir i ser respectuós alhora amb una tradi-
4 L'arquitecte Torras Guardiola es farà càrrec de la direcció de I'Escola d'Arquitectura durant el període 1901-1905, mentre Domènech i Montaner compleix el càrrec de diputat a les Corts per Barcelona, integrat a la candidatura regionalista dels quatre presidents. Torras, en edat avançada quan exerceix com a director de I'Escola d'Arquitectura - té setanta-vuit anys quan n'assumeix la direcció-, dedica el seu mestratge a les assignatures més tècniques, com Resistència de Materials o Hidràulic. La formació de Jujol coincidirà, doncs, amb la direcció de Torras, fet que no modifica, però, la línia de corrent i pensament traçada per Domènech i Montaner: acostament a les tradicions locals, a les formes de I'Edat Mitjana, a l'arquitectura romànica, a l'escola aragonesa i a I'arquitectura mudèjar.

5 Així ho assevera Ràfols, primer biògraf de Jujol, que descriu la influència de Gaudí i del coronament en creu dels seus edificis: "Singular desemboque del arte de Gaudí en el arte frecuentemente juguetón de nuestro arquitecto es la Torre Gibert, en San Juan Despí, Ilamada por Jujol "de la Creu" (ya que una cruz, como en las construcciones gaudinianas, emerge amparadora de lo alto de su más elevada cúpula) $[. .] »,. J . F$. RÀFOLS, «Jujol», Cuadernos de Arquitectura, n. 13, 1950, p. 6.

6 «La importancia que adquiriría en Barcelona el Modernisme [...] sería tan considera- 
ble que la ciudad mereció la calificación de "Atenas del Modernisme", tendencia que no se limitaría al campo de la arquitectura y de las artes, sino que Ilegaría a representar casi una "filosofía", con influencia sobre muchas de las costumbres, ambientes e incluso modos de entender la vida, dentro de la Barcelona de la época. Al ser así una parte importante del carácter vital que impregnaba la sociedad barcelonesa durante los años de juventud y primera madurez de Jujol, resultaría muy difícil para el estudiante y el arquitecto escapar a las influencias derivadas de tal situación sin que por otra parte ello permita considerar su obra como ejemplo representativo de la arquitectura modernista», Carlos Flores, «Josep Maria Jujol, 1999», Arquitectura. Revista del Colegio Oficial de Arquitectos de Madrid, n. 318, 1999, p. 18.

7 Molts dels Ilibres que hereta del seu pare, Andreu Jujol, tracten temes religiosos; per exemple els deu volums de Jean Croiset, Año cristiano, 1877; diverses versions de la Bíblia; 0 Jayme BARón y ARín, Luz de la Fe y de la Ley: entretenimiento christiano entre Desiderio $y$ Electo, maestro y discípulo, 1828.

8 «Hasta en los radiolarios, Gaudí veía a Dios, como también en las líneas de fuerza y en los polígonos funiculares», Juan Eduardo Cirlot, Gaudí, una introducción a su arquitectura, Barcelona, Triangle postals, 2001, p. 19.

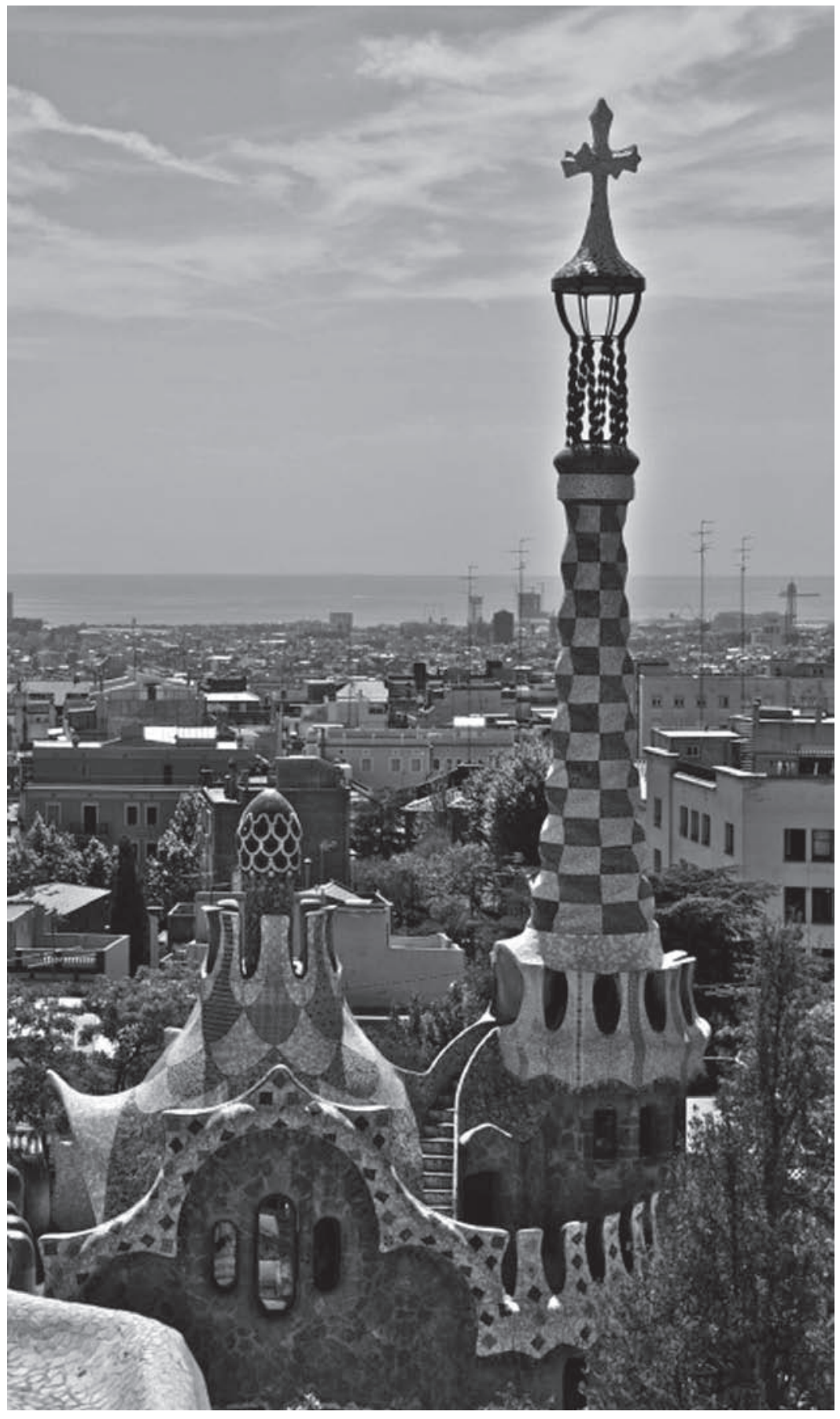

4. Detall de remat al pavelló principal entrada Park Güell. Antoni Gaudí. Fotografia: http://www.vivesoy.com/me-cuido/tendencias/77/barcelona-parque-g\%C3\%BCell. 
ció establerta, a partir dels materials, la posició o els mecanismes que fa servir per a la materialització de la figura.

Miquel Orellana ha assenyalat i documentat el primer dibuix que realitza Jujol a propòsit de la figura d'un arcàngel (fig. 5). Es tracta d'un dibuix d'estudiant en què apareix

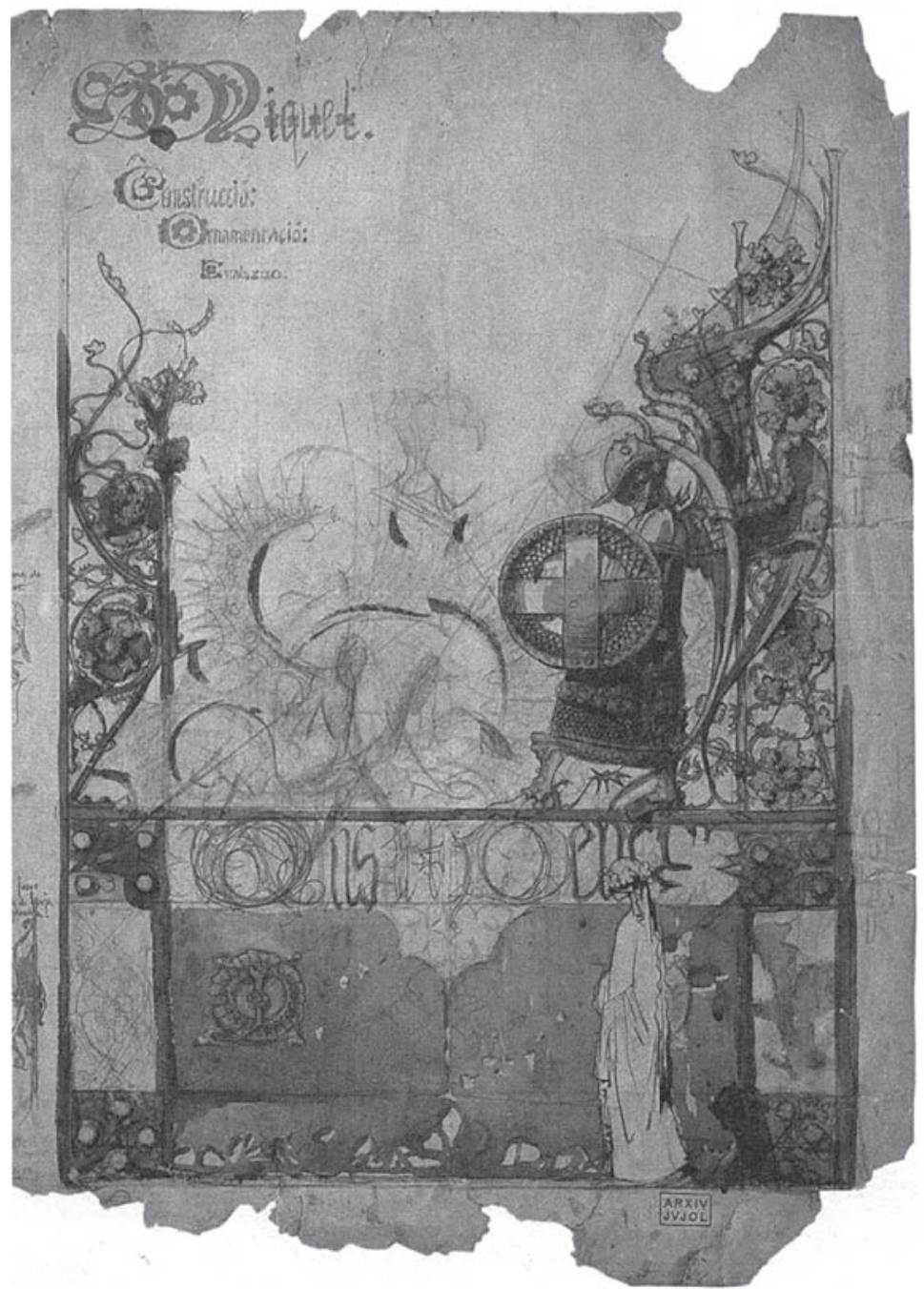

5. Dibuix de l'arcàngel sant Miquel; exercici d'estudiant de Josep M. Jujol. Imatge extreta de Miquel Orellana, «Jujol i l'arcàngel sant Miquel», DC Revista de crítica arquitectònica, n. 5-6, 2001, p. 10. 
9 Miquel Orellana: «Jujol i I'Arcàngel Sant Miquel», DC revista de crítica arquitectònica, n. 5-6, 2001, p. 13.

10 A l'Arxiu Jujol es conserven, entre d'altres, els més de cent dibuixos corresponents al projecte de la reforma de la Casa Bofarull. Un plànol que mostra l'alçat parcial de la torre de I'escala sota de I'àngel, junt amb dues plantes de la mateixa torre, amb data de novembre de 1913 i signat per I'arquitecte Jujol, és el primer document datat que incorpora la figura de l'àngel amb la fesomia definitiva. Igualment es conserven tres dibuixos segons tres moments del muntatge de la figura sobre la coberta de la torre, signats i datats per I'arquitecte el dia 20 de novembre de 1918.

11 «Durant les obres de l'ermita, els dies que Jujol passava a Vallmoll, li agradava compartir vetllades a casa dels Ferré, tot xerrant, berenant confitura (una de les afeccions de Jujol), o sopant... Fou segurament en una d'aquestes vetllades, mentre la gent del poble preparava la festa de la inauguració de l'ermita, quan sorgí la idea. Al fill d'en Ramon Ferré se'l vestiria d'arcàngel per a què sortís a l'acte processional de la festa d'inauguració de la reforma de l'ermita. Jujol, mostrant la seva capacitat d'actuació amb els materials més modestos obsequià el nen amb una obra d'art: un magnífic vestit d'arcàngel fet amb les seves pròpies mans», M. Orellana, op. cit., p. 13.
[...] la figura de l'Arcàngel Sant Miquel. Ens ho corrobora el fet que hi aparegui, a la capçalera esquerra del dibuix, el nom de Miquel i que s'observa la figura d'un guerrer alat que sustenta un escut. [...] L'arcàngel del dibuix té tots els requisits que envolten la figura d'un arcàngel bíblic, un casc, un escut, una cuirassa, unes ales, un drac, però ens falta l'element indispensable: I'espasa. S'intueix en el dibuix un element que podria ser I'espasa però això només són conjectures. El cert és que és I'únic arcàngel que s'ha trobat en la seva obra abans del de Valmoll. ${ }^{9}$

Efectivament, Orellana té raó. Segurament és durant I'època d'estudiant la primera vegada que Jujol estudia la figura de I'arcàngel; només s'equivoca en I'apreciació cronològica, quan data la disfressa d'àngel de Vallmoll com la primera vegada que Jujol construeix aquest personatge. La figura de I'àngel que corona la torre de la Casa Bofarull s'estudia I'any 1913 i s'executa l'any 1918,10 mentre que la disfressa que Jujol dissenya i realitza per al nen de Vallmoll ${ }^{11}$ és sensiblement posterior a I'any 1925. Respecte a la iconografia, Orellana manté que un arcàngel bíblic ha de vestir armadura, casc, escut i espasa. Si aquest darrer element és el que planteja raonables reserves sobre la identitat de la figura que protagonitza el dibuix, aquestes són immediatament eliminades, assenyala Orellana, en comprovar l'existència del rètol de l'extrem superior esquerre on Jujol escriu «S. Miquel». D'altra banda, I'espasa que no acaba de reconèixer en el dibuix es mostra - també únicament esbossada a llapis - com una Ilança en forma de creu, arma amb què l'arcàngel sant Miquel s'enfronta al drac. Com succeeix al dibuix, la dificultat per identificar l'àngel de la Casa Bofarull com a sant Miquel arcàngel o àngel custodi també és una constant no resolta entre els diferents autors que s'hi han referit. Citem-ne alguns com a exemple: Carlos Flores utilitza als seus textos la denominació d' «ángel guardián»; ${ }^{12}$ Manuel Gausa, ${ }^{13}$ Nacho Ferrer, ${ }^{14}$ Vincent Ligtelijn, ${ }^{15}$ Montserrat Duran ${ }^{16}$ i Perejaume ${ }^{17}$ es refereixen a I'àngel sense especificar; Denis Dollens utilitza un neutre «figura», ${ }^{18}$ i Josep Llinàs el descriu com a «Arcàngel San Gabriel». ${ }^{19}$

Esclarir aquest enrenou iconogràfic no és de fàcil solució, atès el confús desenvolupament que ha patit la representació de l'àngel custodi en la iconografia cristiana tot al Ilarg dels segles. Una de les claus per entendre la transformació consisteix a seguir el pas de la veneració litúrgica a una de més popular ${ }^{20}$ originada a la Corona d'Aragó de la baixa Edat Mitjana i que, exterioritzada a les representacions destinades al seu honor, troba suport dins una llarga llista d'imatges entre estatuetes i pintures que creen una complexa iconografia al seu voltant. Segons assenyala Gabriel Llompart, ${ }^{21}$ a la Corona d'Aragó les capitals municipals es constitueixen en 
salvaguardes honrant a les capelles la figura de I'àngel custodi: València li dedica una capella I'any 1392, Tortosa ho fa I'any 1444, Saragossa I'any 1479 i Girona, anomenant-la de Sant Miquel, la constitueix al Ilarg del segle Xv; Mallorca també iniciarà la construcció de la capella de I'àngel I'any 1407 i el municipi de Barcelona pagarà una estàtua a la Porta dels Orbs de la muralla que, amb el temps, passarà a anomenar-se tal com avui dia és coneguda: Portal de l'Àngel. És així com la veneració municipal dels àngels de la guarda, exterioritzada mitjançant comitives i representacions escèniques, ${ }^{22}$ crea un univers de representació pròpia de l'àngel custodi que es concreta en imatges com l'estàtua de l'àngel de Pere ça Anglada (1400-1402) (fig. 6), a la façana vella de Barcelona - designat com a sant Rafael -, la imatge que realitza Pere Joan a les torres de I'entrada a la ciutat de Saragossa (fig. 7), abans de 1450, o l'àngel custodi del Museo de Bellas Artes de Zaragoza, atribuït a Jaume Huguet cap a $1445 .^{23}$

Llompart, a partir de les peces enumerades, realitza un estudi més exhaustiu de les imatges corresponents a les àrees valenciana, aragonesa, catalana i mallorquina, datades entre els segles XV i XIX. Com a representació del custodi, ordena les figuracions en dos grups: el primer faria referència als custodis amb atribut de corona i assots; el segon, a aquells que per atributs ostenten corona i espasa. El doble atribut corona-espasa - 0 el seu equivalent, els assots - és, així, l'element indispensable amb què es reconeix I'àngel custodi. Però si en terres castellanes, ja des de la primera meitat del segle XVI, l'àngel armat és habitual, Llompart assenyala, amb especial atenció, la variant del custodi del mestre Girard representada en un retaule i conservada a l'Arxiu Municipal de Cervera «con un Ángel con pluvial, espada y escudo, que tiene detrás las puertas de la muralla de la ciudad». ${ }^{24} \mathrm{Si}$ en aquest cas particular s'identifica com a sant Miquel una altra imatge, obra de Jaume Huguet (1468-1470) al retaule dit de Sant Bernadí i l'àngel custodi (fig. 8) - conservat actualment al Museu de la Catedral de Barcelona i on apareixen representades les dues figures que donen nom al retaule-, el custodi compareix també armat d'espasa i escut.

La representació de l'arcàngel sant Miquel i de l'àngel custodi es barreja sense que puguem determinar, de manera categòrica, les diferències que separen I'un de I'altre i més si, com recorda Curt Wittlin, ${ }^{25}$ a partir del segle XV només eren permesos els noms de Miquel, Gabriel i Rafael perquè la gent els estimava com a patrons d'esglésies, ciutats, pobles o gremis, en detriment dels àngels anònims. D'altra banda, la introducció oficial del culte als àngels es realitza a partir del llibre d'Eiximenis, Llibre dels àngels (1392), ${ }^{26}$ obra àmpliament divulgada durant els segles XV i XVI i dividida en cinc llibres i dos-cents capítols - el cinquè llibre es dedica íntegra-
12 «[...] Rematándola con un elemento piramidal desarrollado en un lenguaje surrealista-dadaísta coronado por una curiosa figura de ángel guardián a modo de veleta», Carlos Flores, «1914. Casa Bofarull, reforma de un edificio», Quaderns, n. 179-180, novembre 1988 - març 1989, p. 129 .

13 «[...] Les ales d'un àngel en un penell (Bofarull) [...]», Manuel GausA: «Deliri i raó en el disseny de Jujol», Quaderns d'Arquitectura i Urbanisme, n. 174, 1987, p. 95.

14 «[...] Tanto en la torre, coronada por la figura de un ángel perceptible desde uno y otro lado, como en la fachada lateral [...]», Nacho FERRER, «El universo jujoliano», CIC, n. 316, 1998, p. 74.

15 «Jujol got a child to climb on to the 22 meter high tower as a "stand-in" for the angel which was to be the weather vane», Vincent LigTelijn; Rein SaARIsTE, Josep M. Jujol, Rotterdam, 010 Publishers, 1996, p. 40.

16 «[...] L'àngel de la coberta [...]», Montserrat DuRAN, Josep M. Jujol: I'arquitectura amagada, Barcelona, Meteora, 2003, p. 127.

17 «Als peus de l'àngel girant que hi fa de penell [...]», PEREJAUME, Ludwig-Jujol. Què el collage, sinó acostar soledats: Lluís II de Baviera, Josep M. Jujol, Barcelona, La Magrana, 1989 , p. 38.

18 «The figure, once a functioning weather vane $[. .]$.$» .$ Denis Dollens, Five Major Buildings 1913-1923, Nova 
York, Sites Lumen cop., 1994, p. 71 .

19 «[...] para dar lugar a la torre-mirador coronada por el arcángel San Gabriel», Josep LLinÀs, Josep M. Jujol, Colònia, Taschen, 2007, p. 90.

20 «Y es que fue por la fiesta, que la devoción al ángel custodio se desdobló de la liturgia secular que celebraba única y exclusivamente los ángeles en la persona de San Miguel. Hecho que acaeció en los reinos de la Corona de Aragón a lo largo del siglo XV». Gabriel LLOMPART: "El ángel custodio en la Corona de Aragón en la Baja Edad Media (fiesta, teatro, iconografía)», Fiestas y liturgia, Madrid, Casa de Velázquez, Universidad Complutense, 1988, p. 249.

${ }^{21}$ Ibídem, p. 252.

22 Per exemple, amb dades corresponents a l'ordenació municipal de l'any 1446, a València se celebrava un ofici en què una comitiva de I'Ajuntament integra nombrosos nois disfressats d'àngels: "Dos de ellos Ilevan una vara plateada. Son mayores. De unos dieciocho años. Son los verguers. Siguen en parejas otros dieciocho chicos de unos doce años. Se trata de los representantes de los nueve coros angélicos. [...] Por último viene la presidencia de la comitiva: en primer término un joven ángel - de unos dieciocho años - qui porta una pavesina ab lo senyal de la ciutat amb una correcha que li devalla per 10 coll faent la via al costat devall lo braç sinistra. Luego sigue 10 gran àngel custodi, vestit ab

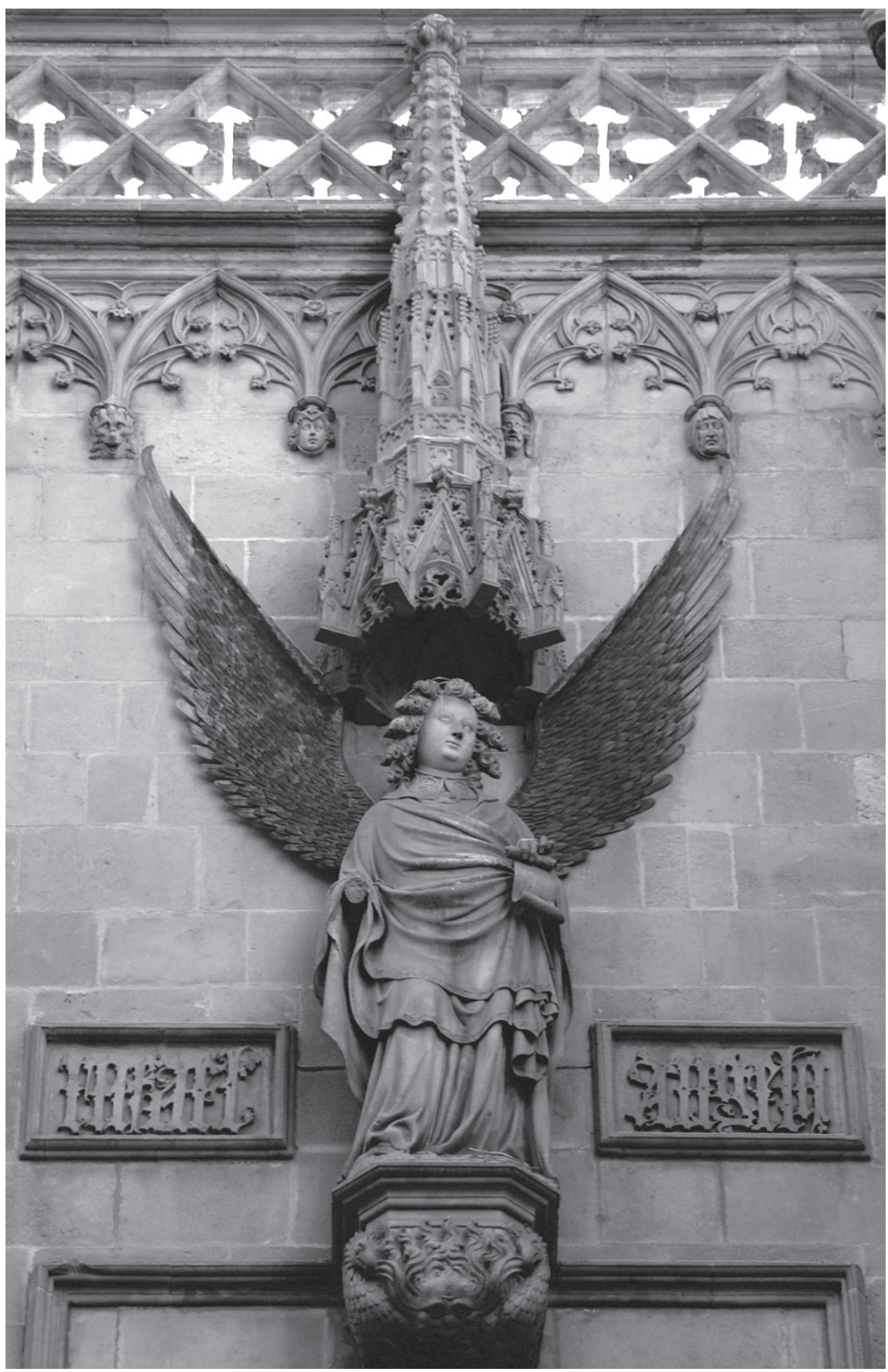

6. Arcàngel sant Rafael, obra de Pere ça Anglada (1400-1402) a la façana vella de l'Ajuntament de Barcelona. Fotografia: http://upload.wikimedia.org/wikipedia/commons/f/fd/Ajuntament_ de_Barcelona_-_001.jpg. 
ment a l'arcàngel sant Miquel. Això explicaria, en gran mesura, I'empenta que experimenta la devoció a Catalunya de I'àngel, ja que les dotze primeres esglésies dedicades al seu culte s'inicien ja als segles X-XI, mentre paral·lelament se succeiran les peregrinacions al Mont-SaintMichel, de les quals estan documentades donacions a la seva veneració des del segle XI. ${ }^{27}$ L'evidència de I'arrelament que a Catalunya mostra I'arcàngel sant Miquel no evita que, alhora, la tradició popular i la celebració festiva provoquin un desdoblament que derivarà en I'encreuament i la barreja de la iconografia; aquesta bifurcació genera, com a resultat, una representació compartida entre l'arcàngel i l'àngel custodi.

Enfront d'aquest ampli nombre de matisos que la representació del custodi abasta, formular una pregunta, no exempta d'innocència, pot aportar bons resultats: com construeix, formalitza i defineix Jujol I'àngel penell que col·loca sobre la coberta de la torre mirador de la Casa Bofarull? Respondre aquesta qüestió enllaça amb el segon assumpte formulat a l'inici, en relació amb l'aparença, la posició, la dimensió i el mecanisme de I'àngel. Repassem ara l'àngel de la Casa Bofarull des dels seus principis constitutius.

\section{Dimensions i percepció}

En essència, un penell consta de dos elements: I'eix vertical, que uneix les diferents parts amb la base, i el cos mòbil, que gira accionat per l'empenta del vent. Buscar l'origen de tal artefacte, quan el cos mòbil està constituït

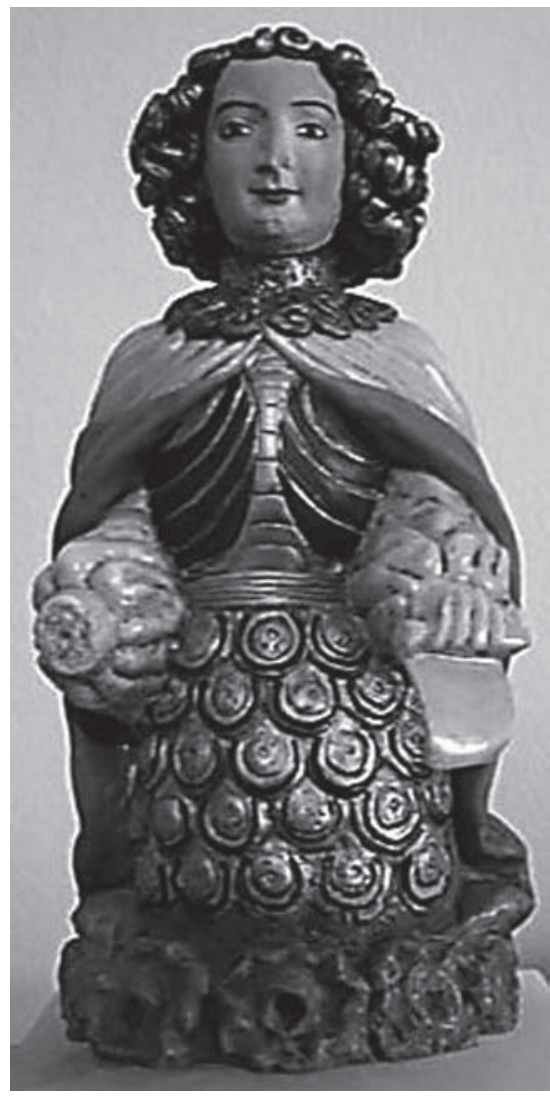

7. Àngel custodi, obra de Pere Joan, cap a 1440. L'àngel, de mig cos, sobresurt d'una base de núvols. A la mà esquerra sosté una cartel.la, i la mà dreta s'ha perdut. Aquest àngel s'associa al que hi havia a la porta superior de l'avui desapareguda porta del Pont o de l'Àngel. Actualment es conserva al Museo de Zaragoza. Fotografia: http://www.santoangel.info/custodio-zaragoza. htm.

solemne camis de cendat vermell ab guants vermells, amb una molt bella e singular testa en lo cap, e sobre lo dit camis porta una notable real sobrevesta d'or e flama, la qual va solta e delliure [...]. El cortejo que precede a los jurados sale de las casas consistoriales en dirección a la vecina catedral cantando la siguiente cantinela: Àngel custodi de Déu infinit / guardau la ciutat de dia y de nit I per a que no entre lo mal esperit», Gabriel LLOMPART, op. cit., p. 253-254.

23 Ibídem, p. 259.

24 Ibídem, p. 268.

25 Francesc Eiximenis, De Sant Miquel Arcàngel, Curt Wittlin (ed.), Barcelona, Curial, 1983, p. 11.

26 «Si ací el llibre d'Eiximenis havia fomentat el culte dels àngels, en altres llocs un interès ja existent pels àngels féu que hom se'l vagi copiar o traduir. [(...)] que hom hagi traduït i imprès el llibre sencer, i no tan sols la part dedicada a I'arcàngel, prova l'admiració pel text complet... o almenys un cert respecte davant el conjunt d'una obra literària de temps i terres Ilunyanes», Ibídem, p. 10-12.

27 «Las numerosas capillas de castillos que se le dedican [a San Miguel] en algunas zonas de la Cataluña de los siglos XIXII, atestiguan una particular devoción hacia él por parte del estamento militar. Los condes de Urgell se distinguen desde el siglo x por la especial atención que prodigan a los monasterios bajo su advocación. Su ayuda 
será invocada con frecuencia por reyes, nobles y caballeros. En 1094 el rey Pedro I le atribuye la victoria ante Huesca y el rey Alfonso reconquista Zaragoza con su ayuda. Balaguer cae en el 1101 y se pone a la ciudad bajo su protección. El 8 de mayo de 1162, fiesta del arcángel, Escornalbou es reconquistada, y el 29 de septiembre de 1283, otra de las fiestas arcangélicas, los cristianos entran en Valencia. A su calidad de intercesor añade pues la de símbolo del espíritu de cruzada», Paulino Rodríguez BarRAL, «Eiximenis y la iconografía de San Miguel en el gótico catalán», Annals de l'Institut d'Estudis Gironins, vol. XLVI, 2005, p. 111.

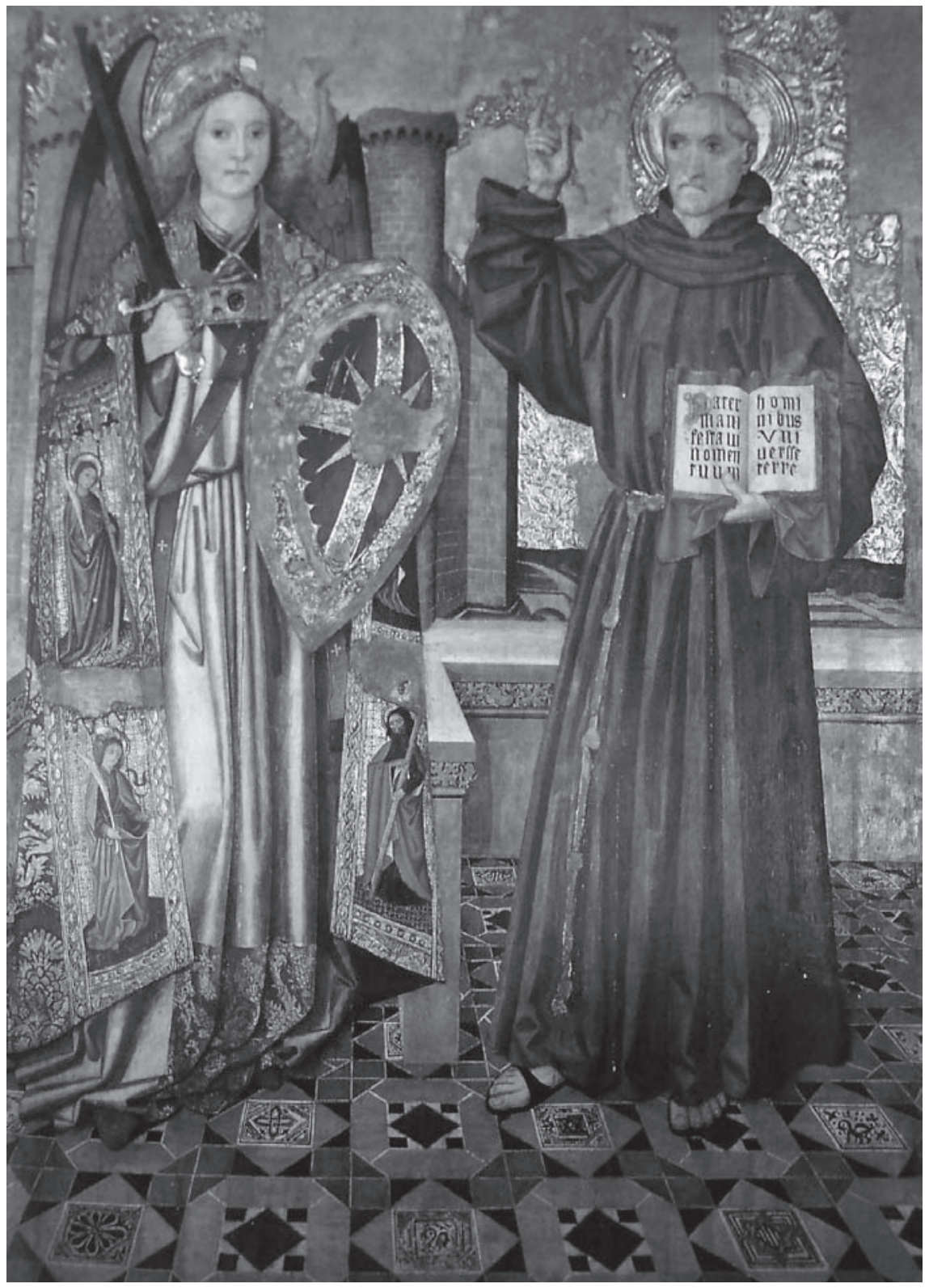

8. Detall del retaule de Jaume Huguet, Sant Bernadí i l'àngel custodi (1468-1470), amb espasa i escut. Retaule provinent de la capella d'esparters i vidriers de la Catedral de Barcelona. Museu de la Catedral de Barcelona. Imatge extreta de Jaume Huguet, 500 anys, Barcelona, Generalitat de Catalunya, Departament de Cultura, 1993, p. 177.

per una estàtua de grans dimensions, ens acostarà a la comprensió de l'àngel penell. Una de les primeres estàtues utilitzades com a penell de les quals es 
té constància és la que apareix al tractat arquitectònic de Vitruvi quan escriu, al capítol sis, a propòsit dels vents, dedicat a la divisió i distribució de les obres dins les muralles:

[...] Andrónico Cirrestres que, como demostración, levantó en Atenas una torre octogonal de mármol y en cada uno de sus lados hizo esculpir la imagen de cada viento de cara hacia donde sopla; sobre esta torre, rematada por una pirámide también de mármol, y en su cima colocó un Tritón de bronce que en su mano derecha extendida tenía una varita y estaba dispuesto de modo que, al girar este Tritón a impulso del viento que soplara, la varita viniese a caer sobre la imagen del viento que reinaba. ${ }^{28}$

Vitruvi assenyala Andrònic Cirrestes, astrònom i arquitecte grec, com el primer a construir un penell de característiques semblants. Dues idees podem fer constar: la primera, literal, la utilització primigènia d'una estàtua - en el cas d'Andrònic, una figura mitològica - com a penell; la segona, la coincidència geomètrica del suport de les dues figures, una piràmide, tant sobre la torre erigida per Andrònic com la que defineix la coberta de la torre mirador de la Casa Bofarull. La relació que pogués mantenir Jujol amb un tractat clàssic com el text de Vitruvi és, segurament, circumstancial; però està fora de dubte el coneixement que n'havia de tenir donada la tradicional difusió del text i la contribució al coneixement del patrimoni de I'antiguitat clàssica. És possible, així, pensar que el manual d'arquitectura hauria estat consultat, en algun moment, tant des del seu aprenentatge acadèmic com des de les classes d'història de l'art, o durant el posterior exercici professional.

Però si la torre d'Andrònic es documenta com un dels primers penells amb figura, un segon exemple el descriu Francesco Colonna ${ }^{29}$ a Hypnerotomachia Polifile o Somni de Polífil, durant la narració del somni que el transporta a la vall on una portentosa piràmide culmina igualment amb una figura el mecanisme de la qual li permet girar amb l'empenta del vent:

Esta inmensa y terrible pirámide se alzaba a punta de diamante en gradas de admirable y exquisita simetría y tenía mil cuatrocientos diez escalones, menos diez de ellos destinados a terminar la punta.

[...] Sobre ellos se alzaba el obelisco, firmísimamente superpuesto. [...] Estaba hecho de granito rojo de Tebas y en sus caras había jeroglíficos egipcios notablemente esculpidos; y era liso, terso y lustroso como un espejo.

En su punta, sobrepuesta con gran habilidad y arte, descansaba una base de oricalco en la que además había una máquina giratoria en forma de cupulilla fijada sobre un perno o eje que retenía la imagen de una ninfa, obra ele-
28 Citat a Rosario VILLEGAS (coord.), El Giraldillo: la veleta del tiempo: proyecto de investigación e intervención, Sevilla, Junta de Andalucía, Consejería de Cultura, Instituto Andaluz del Patrimonio Histórico, 2003, p. 38 i 51.

29 Francesco Colonna, Sueño de Polífilo, Pilar Pedraza (ed.), Barcelona, Acantilado, 2008. Citat a Rosario VILLEGAS, op. cit., p. 51. L'obra és de caràcter enciclopèdic en tant que se succeeixen descripcions arqueològiques, botàniques, arquitectòniques, litúrgiques, epigràfiques o gemmològiques. La trama principal es desenvolupa a través del somni de Polífil, que descriu un viatge de caràcter amatori, al qual s'introdueix Polia a través del somni. 
30 Ibídem, p. 96.

31 Ibídem, p. 48.

32 Anomenar aquests exemples i no d'altres és de fàcil justificació: la figura que corona la Giralda, el Giraldillo, es constitueix com la més gran de les estàtues del segle XVI coronant un edifici i, segons alguns autors, inspirada directament en la solució d'Andrònic Cirrestes. Els altres exemples, situats tots a la comarca del Penedès, identifiquen aquest coronament com a símbol identitari i permeten intuir la solució com a arrelada i establerta a la geografia. La proximitat física amb Tarragona autoritza a pensar en un coneixement $d^{\prime}$ aquests darrers exemples per part de Jujol.

33 «Coronando la pirámide de cubierta, un peculiar ángelveleta, de gran tamaño, en chapa de cobre, diseñado por el arquitecto», Carlos FLoRES, Arquitectura. Revista del Colegio Oficial de Arquitectos de Madrid, op. cit., p. 17.

34 Les dades es troben recoIlides en un petit dibuix de l'esquema estructural de I'àngel, on apunta Jujol: "alsada total 1.60; Ample d'espatlles 0.65». El dibuix no està datat i es conserva a I'Arxiu Jujol. gante de la materia antes mencionada, capaz de llenar de estupor a quien la miraba atentamente y con mirada insistente. Sus proporciones eran tan estudiadas que permitían verla de tamaño natural en el aire, mirándola desde abajo. Además del tamaño de aquella estatua, era cosa que llenaba de admiración considerar con qué atrevimiento había sido elevada y puesta en el aire a tanta altura. ${ }^{30}$

Encara que I'edició francesa de la Hypnerotomachia, escrita I'any 1883 per l'erudit Claude Popelin, pogués haver estat consultada per Jujol en alguna de les biblioteques que utilitzava habitualment, es tractava d'una obra de mínima difusió i coneixement singular — tot i això, a Espanya trobarà reflex als relleus d'un dels costats del claustre de la Universitat de Salamanca, on es reconeixen diversos dels gravats que il.|lustren l'obra. ${ }^{31}$ No podem saber si Jujol coneixia l'obra, i fins i tot seria difícil donades les poques edicions presents al nostre país, però l'interès es troba en la descripció que Colonna, al seu minuciós relat, afegeix a la definició mecànica del penell: les grans proporcions de l'estàtua que, a la funció meteorològica i al-legòrica, suma la característica d'enlluernar per les dimensions - retinguem per uns instants I'observació sobre les dimensions. Però si aquests dos testimonis tenen un indubtable valor testimonial com a origen remot de l'ús de I'estatuària complint funcions de penell, no hem de perdre de vista, en qualsevol cas, referents més pròxims, situacions construïdes que, per proximitat geogràfica, haurien pogut significar per a Jujol un antecedent amb què legitimar I'ús de l'àngel a la Casa. Els exemples autòctons es troben tots en edificis de caràcter religiós: des dels situats en un context nacional, en què existeix una petjada mudèjar, com és el cas de l'església de San Sebastián d’Antequera o la Giralda de la catedral de Santa María, a Sevilla - I'exemple més universalment conegut - , fins a les torres campanar d'esglésies més locals i pròximes a l'imaginari de Jujol com són les de Sant Bartomeu a Albinyana, Sant Ramon de Penyafort, Sant Salvador del Vendrell o Santa Maria a Vilafranca del Penedès. ${ }^{32}$

Tornant al volum de la figura, Carlos Flores $^{33}$ ha assenyalat una característica que coincideix, en la perspicàcia visual, amb I'anterior descripció que Colonna realitzava sobre l'estàtua penell que veu Polífil: les enormes dimensions que permeten observar-la, encara elevada, en les veritables proporcions. Verificar les dimensions de l'àngel de la Casa Bofarull serà, doncs, operació obligada per continuar la nostra anàlisi. Comparant dades objectives descobrim que, tot i que I'àngel de Jujol - del qual coneixem les mesures, un metre amb seixanta-cinc centímetres d'alçada des dels peus fins al cap_ 34 és el de menor dimensió dels exemples proposats, és, en realitat, el que es percep com el més gran. Comparar les proporcions 


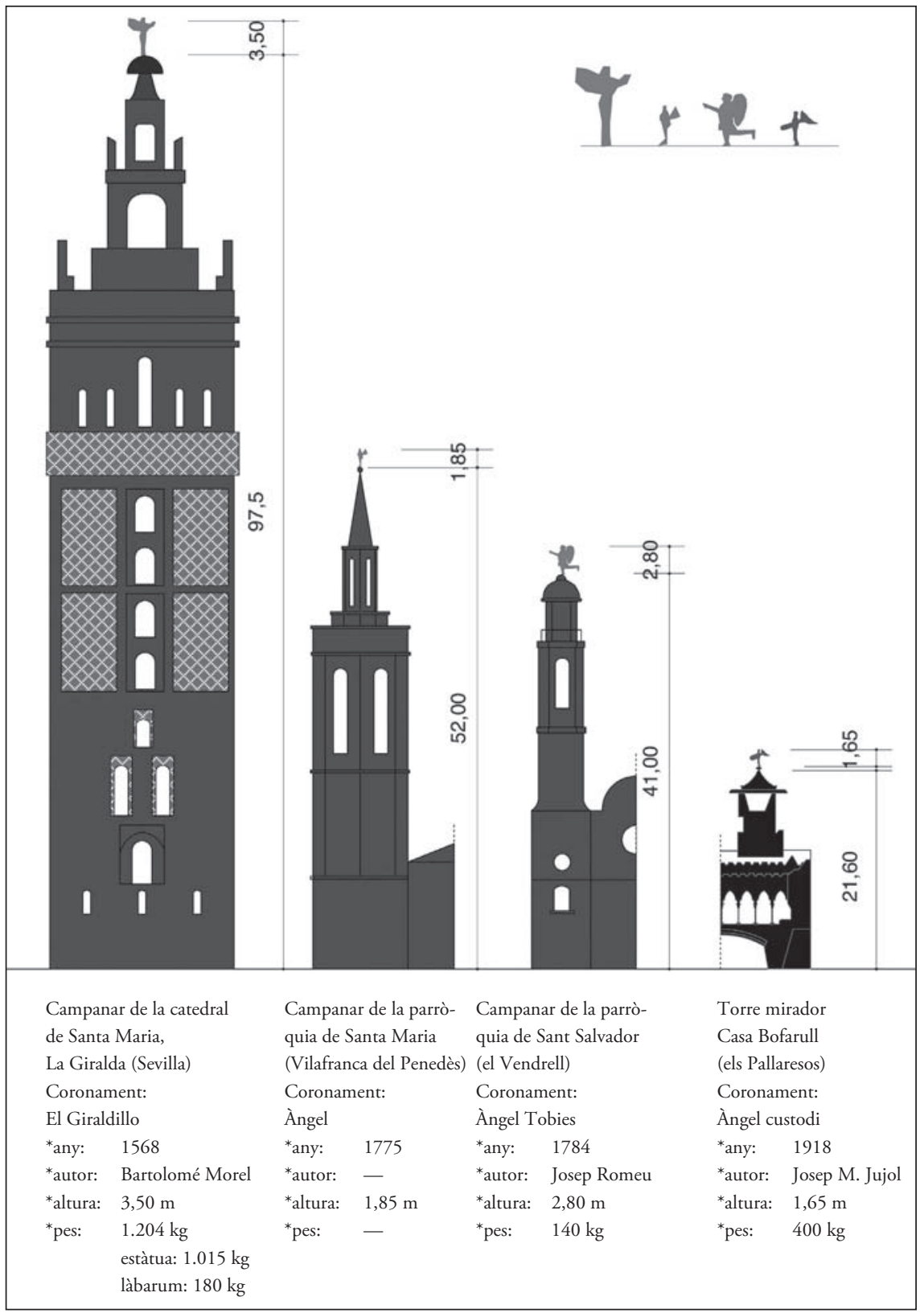

9. Comparativa entre diversos exemples d'àngels penell. Imatge: elaboració pròpia a partir de les dades obtingudes de Campaners i campanes de l'Alt i el Baix Penedès, Vilafranca del Penedès, Penedès publicacions, 1996; Rosario Villegas SÁnchez, El Giraldillo: la veleta del tiempo, Sevilla, Junta de Andalucía, Consejería de Cultura, Instituto Andaluz del Patrimonio Histórico, 2003; entrevistes amb Francesc Salvat, responsable de la restauració de l'àngel de la Casa Bofarull, i Xavier Mercader, responsable de la restauració de l'àngel del Vendrell. 
35 Josep M. JuJoL fill, La arquitectura de Josep M. Jujol, Barcelona, La Gaya Ciencia, 1974, p. 89. d'alguns dels exemples esmentats (fig. 9) és suficient per comprovar que la relació entre I'alçada total de I'edifici que suporta l'àngel i I'alçada de I'àngel és quasi d'un $10 \%$ en el cas de I'àngel dissenyat per Jujol, mentre que al Giraldillo, com al campanar de Santa Maria de Vilafranca, aquesta mateixa relació és tan sols d'un 3,5\%; i, finalment, d'un 6,5\% en el cas de l'àngel del Vendrell. Les dades són clares i l'evidència física sembla irrefutable: la proporció entre alçada total i alçada de l'àngel i la distància en termes absoluts que separa del sòl I'àngel de Jujol, determinen la percepció d'una figura que, sent de dimensions relativament modestes, es fa veure més gran.

La pregunta es planteja, de nou, necessària: com de gran cal que sigui una figura per ser raonablement observable des de qualsevol punt i, alhora, ser reconeguda? Segons explica el fill de I'arquitecte,

Antes de construir el ángel ordenó a un muchachito del pueblo que ayudaba al albañil que subiese sobre la cúspide del mirador, mientras él lo contemplaba desde el extremo del pueblo, al principio del camino del cementerio, para comprobar la medida que habría que dar a la figura. ${ }^{35}$

La massa de l'àngel identifica una manera de treballar basada en la concreció experimental i la percepció visual. L'arquitecte pren distància, utilitza un jove del Iloc com a model vivent i dedueix I'escala que necessita la figura per ser reconeguda des de la distància, un radi de dos-cents metres que abasta diametralment tots els inicis dels camins que arriben als Pallaresos. Però el penell requereix un element que ofereixi resistència al vent per actuar com a tal, i si alguna cosa identifica la figura de l'àngel, són les seves ales. És obvi que Jujol vol que l'espectador es detingui i reconegui I'estàtua com a referent visual, orientant el visitant, marcant la direcció del vent, assenyalant la intervenció a la Casa Bofarull i erigint-se en símbol protector dels Pallaresos. Encara que, per tal que així sigui, el volum de I'àngel guanyi en envergadura.

La resposta de Jujol és tan evident i funcional com plàstica en la materialització: les ales desplegades donaran a l'àngel suficient contrapunt geomètric per permetre el gir de la figura per l'acció del vent; des dels retalls en forma de plomes que repunten la vora de les ales fins a la superposició de diverses planxes metàl-liques com a solució, la formalització de l'àngel està pensada per representar un instant congelat de l'impuls que I'acompanya quan reposa sobre la casa. D'altra banda, la disposició vertical augmenta l'altura de l'àngel en quaranta centímetres, resultant en un total d'uns dos metres d'alçada des dels peus fins al punt més elevat de les ales. En definitiva, un àngel - ales incloses - de dos metres, a tan sols 


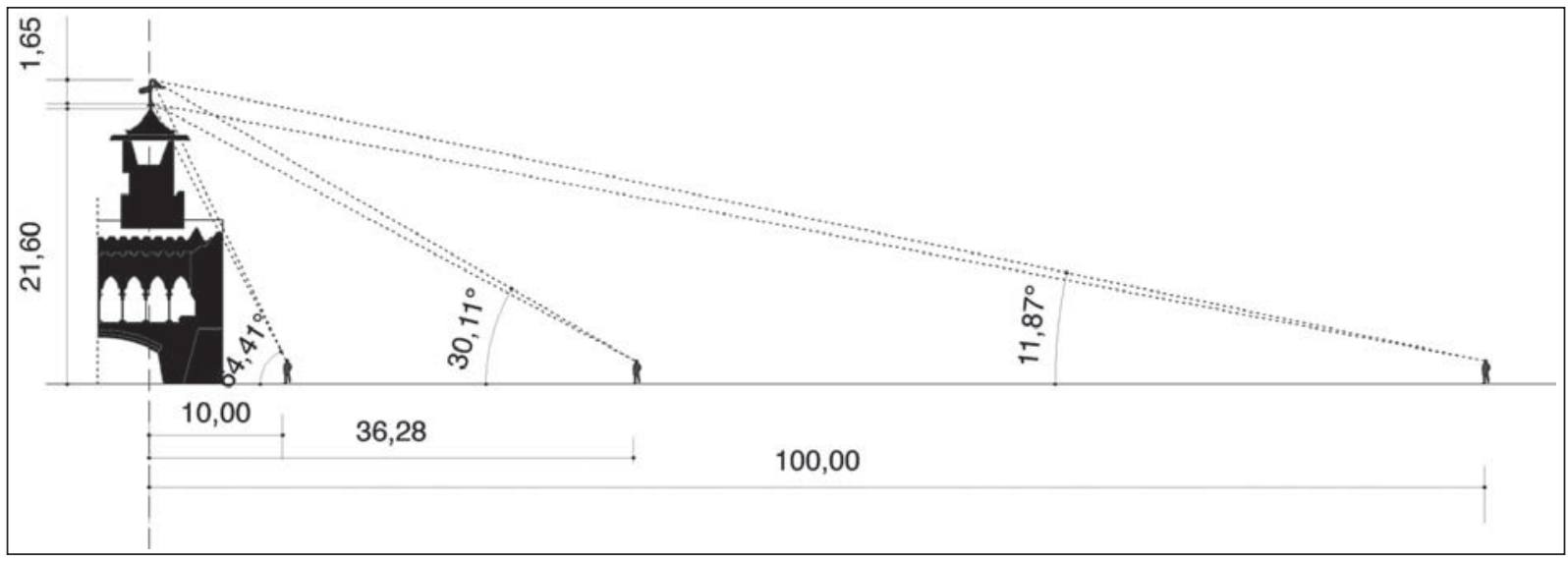

10. Esquema explicatiu sobre la percepció d'un element vertical segons la distància de l'observador. La dimensió de la imatge depèn de la dimensió de l'objecte i de la distància a què es troba; per tant, de l'angle amb què l'objecte és percebut des de l'ull. Se suposen tres casos: a) L'observador se situa a $10 \mathrm{~m}$ respecte a la vertical que forma la posició de l'àngel; l'angle d'obertura es xifra en $64,41^{\circ}$, més gran que l'angle habitual de visió humana, estimat entre $30^{\circ} \mathrm{i} 45^{\circ}$. L'efecte és una percepció més gran que la realitat. b) L'observador se situa a 36,28 m, distància ideal per percebre el conjunt en la justa mesura. c) L'observador se situa a $100 \mathrm{~m}$, distància on l'angle de visió es xifra en $11,87^{\circ}$, cosa que genera una percepció de les dimensions totals menor a les reals. Fins a una distància d'aproximadament $40 \mathrm{~m}$, l'observador que miri cap a l'àngel el registra com a més gran del que és en realitat, donada la dificultat que té el cervell per assimilar unes dimensions que no pot abastar des del seu angle de visió habitual. Com més gran és l'angle aparent de visió, més gran és la imatge que es forma a la retina i més gran ens sembla l'objecte que observem. Imatge: elaboració de l'autor.

vint-i-un metres d'alçada, no pot sinó coincidir amb la percepció de Polífil i identificar aquestes dimensions com a naturals ${ }^{36}$ (fig. 10).

\section{Estructura, mecanisme i materials}

Un fragment de campana, utilitzat com a peanya, és l'element intermedi que serveix de base a l'estàtua i que és travessat per un plançó vertical de ferro per subjectar la figura i ancorar-se a la piràmide (fig. 11). La peanya, que Jujol imagina esfèrica, veurà modificada la geometria en una decisió emparada, una vegada més, tant pel material utilitzat - una vella campana, de geometria oberta i no tancada com una esfera-com pels mitjans de què disposa. Si el referent ortodox es troba sempre present al pensament de Jujol - el contacte de la figura de I'àngel, baixant des del cel a la Terra, hauria de produir-se a través d'una esfera, metàfora de la Terra-, n'hi ha prou d'observar la intensitat en el dibuix de la solució final per evidenciar el pragmatisme amb què Jujol admet i rectifica una solució establerta, incorporant una variant sense trair l'esperit original.
36 Això s'explica per la correspondència geomètrica entre I'angle visual que utilitza la visió humana i la proporció que conserva una figura en alçada, respecte a la distància d'observació. Quan I'angle de visió s'aproxima als trenta graus, la percepció és pràcticament equivalent a les mesures reals de la figura observada. 

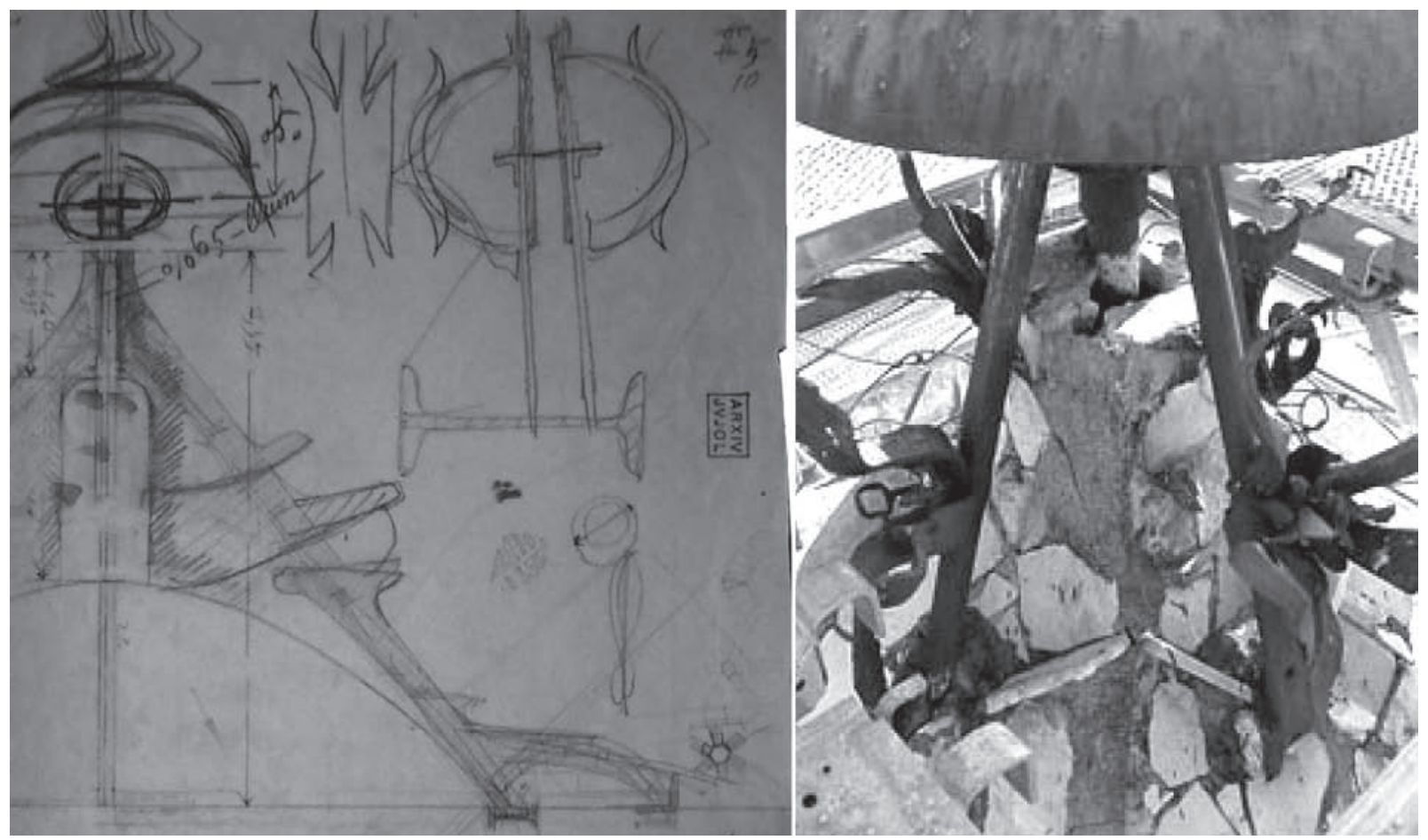

11. Fragment de plànol de Josep M. Jujol i estat del suport abans de la restauració de l'any 2000. La posició dels perfils s'adequa a la geometria de la piràmide de coberta, de menors dimensions que les previstes en el projecte. Fotografia cedida per Francesc Salvat.

Una segona modificació, duta a terme segurament durant el procés de forja del suport de l'estàtua, es manifesta en la reducció de les mesures de la base que formen els perfils per donar estabilitat al conjunt. El dibuix previ, elaborat per Jujol, defineix una distància entre el suport campana i el punt de suport amb la base de la piràmide que subjecta el pern interior de la figura, més gran que l'executat finalment. No són, però, aquests matisos, comuns al procés de qualsevol obra en el trànsit que va des del paper fins a la realització material, allò que crida l'atenció, sinó el fet que Jujol associï ornament i funcionalitat en una operació simultània. L'exemple es materialitza en el mateix suport comentat: a mitja alçada dels perfils que van des del centre de la campana fins al punt d'ancoratge de la piràmide, s'observen uns peus intermedis que, al dibuix, apareixen com a sobresortints. En obra, acaben per convertir-se en motius vegetals, també de ferro, que per dimensió i solidesa fan difícil pensar només en motius ornamentals i sí, amb més probabilitat d'encert, en graons que facilitin l'accés a la base de la campana per al seu manteniment o neteja. 
El dispositiu que permet el funcionament de I'estàtua com a penell consisteix en un èmbol central de ferro de vuit centímetres de diàmetre, que subjecta i fixa la figura a la base de la campana; aquest ferro central forma l'eix sobre el qual gira l'àngel mitjançant un mecanisme de coixinets, la rotació dels quals no depèn del pes de la figura vertical, sinó d’una força mínima exercida a manera d'empenta lateral, com és el vent sobre les ales de I'àngel. Tant I'èmbol com I'estructura que formava l'esquelet de les ales (fig. 12 i 13) es van realitzar a partir de tubs, ferros i platines o peces de forma rectangular i gruix reduït, producte de materials de rebuig i fragments de peces descartades. ${ }^{37}$ És habitual trobar en l'obra de Jujol components metàl·lics reutilitzats d'una manera o d'una altra, ja sigui com a estructura -en el cas dels pilars metàllics del Teatre del Patronat Obrer-, com a estructura interna d'un mur de tancament -el somier contingut dins la tanca de formigó que limita I'església de Montferri- o en operacions més ornamentals, com a les reixes de la Casa Bofarull, mobiliari - làmpada de Vistabella_, portes - Casa Negre i Casa Bofarull-, etc.

Una imatge en detall mostra el material de base no especificat en els croquis que de I'estructura realitza Jujol: la pe// de l'àngel custodi s'elabora a partir d'una barreja d'àrids i morter - lligats amb filferro per assegurar-ne la subjecció durant l'assecat del material- que dóna com a resultat una pell de gairebé dos centímetres de gruix. Aquesta configuració
37 Ho hem pogut comprovar gràcies a les imatges que Francesc Salvat, propietari de l'empresa Talleres Salvat S.L. i responsable de la restauració de la Casa Bofarull I'any 2000, ens ha permès estudiar. 
38 Segons la biografia escrita pel seu fill, «En el verano del 18, teniendo que hacer el ángel para la Casa Bofarull, pidió a los padres de la muchacha que le permitieran sacar una mascarilla de su rostro. Así se hizo $y$, junto a unos brazos y piernas, que el propio arquitecto moldeó, se construyó una figura de tamaño natural, sin cuerpo, con la túnica de la plancha de cobre [...]», Josep M. JuJoL fill, op. cit., p. 89.

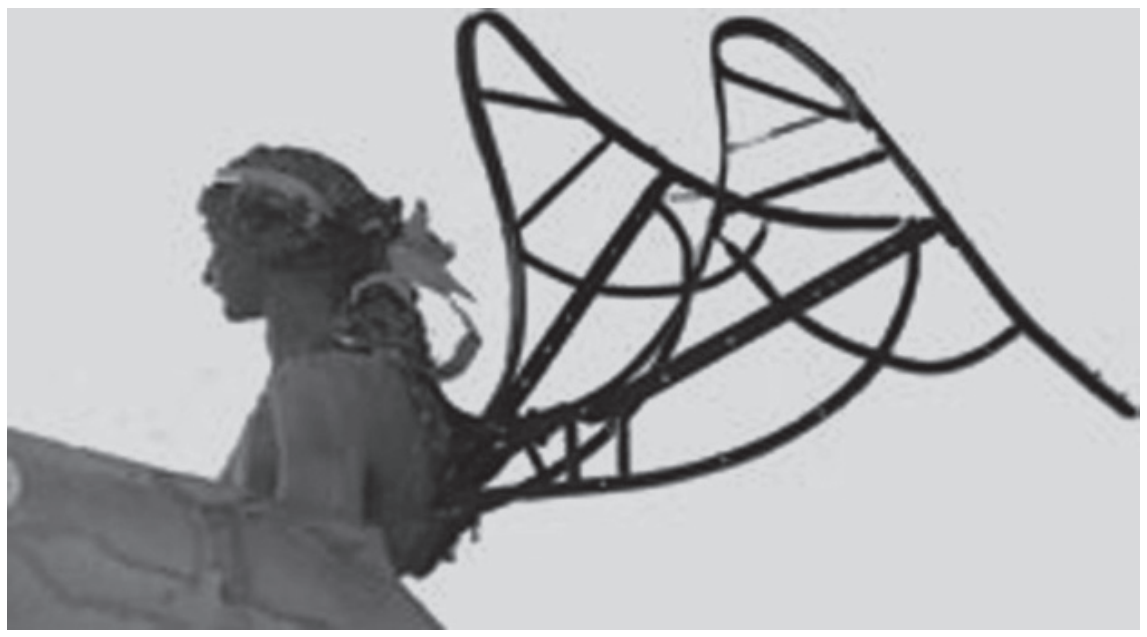

13. Detall de l'estructura de les ales, un cop recompostes i restaurades, moments abans de muntar el revestiment original. Fotografia cedida per Francesc Salvat.

explica l'elevat pes de l'estàtua - d'aproximadament uns quatre-cents quilograms - i, consegüentment, les dimensions de les ales que oferiran la resistència necessària per facilitar la rotació de l'àngel a l'empenta del vent. No era habitual utilitzar un material similar en una estàtua que havia de ser suportada a l'aire, a causa de l'elevat pes que suposava; més habitual era fer servir planxa de coure, deixant buit l'interior del cos de l'estàtua. Encara valorant l'inconvenient del pes, I'elecció de construir una pell amb aquesta barreja de sorra, calç, aigua i pedres ofereix altres virtuts no alienes a la seva manera de fer. La ductilitat del compost permet a Jujol tractar la figura com allò que és: una escultura amb què modelar un cos realista, suficientment immune als agents atmosfèrics, recognoscible a partir de la forma i sobre la qual poder assenyalar, de manera fàcil i durant l'execució, el nom de la icona. Tot un conjunt de característiques que deriven en l'elecció d'un material la manipulació del qual no necessita ni matèria primera costosa, ni una complicada posada en obra, ni una especial col·laboració tècnica en I'execució que impedeixi, al mateix Jujol, fer-se personalment càrrec del modelatge de l'estàtua. ${ }^{38}$

Jujol efectuarà dues incisions sobre el cos de l'àngel: la primera marca, sobre la cintura, elimina qualsevol dubte en relació amb la identitat de la figura: «Àngel Custodi»; la segona incisió, seguint la vertical cap amunt, distingeix una creu sobre el pit adornada a les seves puntes amb motius vegetals (fig. 14). Encara acceptant que I'arcàngel sant Miquel exerceix tanmateix $d$ 'àngel custodi, sabem que és reconegut tradicionalment com el guardià dels exèrcits cristians contra els enemics de I'Església; i que també 


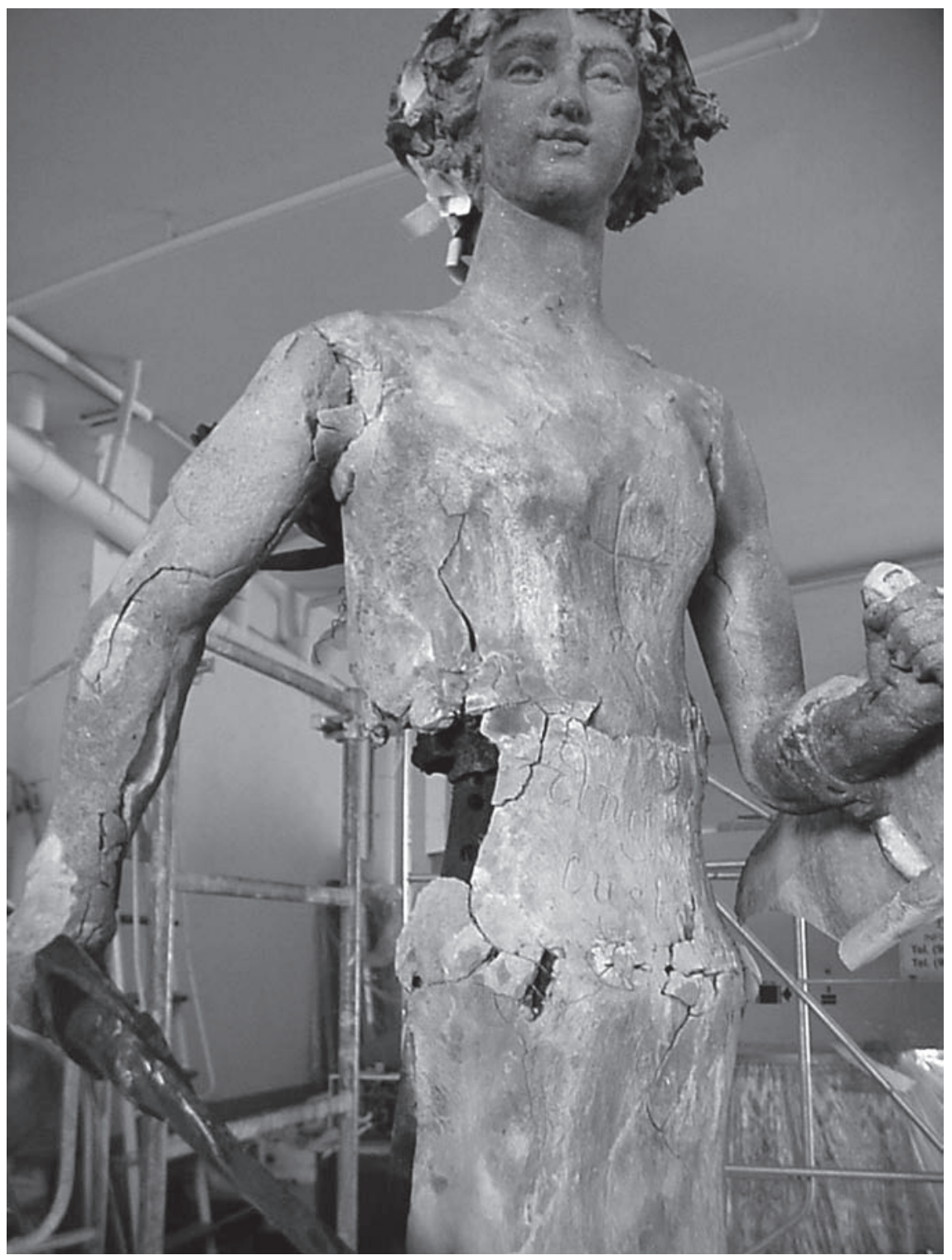

14. Detall de la cintura de l'àngel, desproveïda de l'armadura durant el procés d'estudi previ a la restauració de l'any 2000. Fotografia cedida per Francesc Salvat.

la tradició està profundament arrelada en l'imaginari popular català, per la qual cosa no deixa de sorprendre que el mateix Jujol identifiqui I'estàtua únicament com a «Àngel Custodi» i no com a sant Miquel. Explorem, doncs, finalment, els trets principals que definiran la iconografia de I'àngel dissenyat per Jujol. 
39 «Nel Vecchio Testamento I'angelo è indicato della parola ebraica mal'akh, che significa "messaggero". Si tradusce il termine in greco con il termine angelos, che significa "colui che annuncia"; la parola greca fu introdutta quindi nelle lingue moderne nelle forme angelo, angel, Engel, ange», Fritz SAXL, Lastoria delle immagini, Bari, Laterza, 2000, p. 10.

40 Jutges 13:16-21. Citat a

Fritz SAXL, op. cit.

41 Josuè 5:13. Ibídem, p. 11.

\section{Representació i descripció dels atributs}

Actualment estem molt familiaritzats amb la representació de I'àngel com una figura alada, encara que no sempre fou així. Fritz Saxl ens explica que el missatger ${ }^{39}$ ja apareix en el Llibre dels Jutges, en una versió no alada; la clau radica en la darrera frase de la narració, on I'àngel es desplaça sobre una flama, quelcom que considera absurd si disposés d'ales:

Però contestà I'àngel de Jahvè a Manóah: Encara que m'acullis no puc pas menjar el teu pa; ara, si vols fer un holocaust a Jahvè, fes-lo. - Perquè Manóah no s'havia adonat que era l'àngel de Jahvè. - Manóah preguntà a I'àngel de Jahvè: Quin és el teu nom, per tant que quan això es realitzarà et puguem honrar? Li contestà I'àngel de Jahvè: Per què em preguntes pel meu nom? És impenetrable.

Manóah va prendre un xai i I'ofrena, i els oferí sobre una roca en holocaust a Jahvè, que fa meravelles. I en pujar la flama de I'altar cap al cel, l'àngel de Jahvè pujà també en la flama de l'altar. Manóah i la seva muller en veure-ho caigueren faç en terra. ${ }^{40}$

Els primers cristians representen l'àngel com un guerrer, segons narra el Llibre de Josuè:

Mentre Josuè es trobava prop de Jericó, alçà els ulls i veié un home dret davant seu, que tenia una espasa nua a la mà. Josuè anà cap a ell i li digué: Ets dels nostres o dels enemics? Respongué: No! Jo sóc el capità de l'exèrcit de Jahvè, ara arribo. Josuè, abaixant el cap fins a terra, I'adorà i li digué: Què diu el meu Senyor al seu servent? I el capità de l'exèrcit de Jahvè va dir a Josuè: Treu-te les sandàlies, perquè el lloc que trepitges és sant. I Josué així ho féu. ${ }^{41}$

L'escena es troba representada a Santa Maria Maggiore de Roma sobre un mosaic del segle $v$, descrit com un guerrer; la contradicció sobrevé quan una representació posterior mostra l'àngel amb ales. La transformació no té sentit perquè, com diu Saxl, si Josuè hagués vist les ales mai s'hauria qüestionat sobre la naturalesa de I'home que se li acostà. El moment, doncs, en què s'introdueix la versió alada té una gènesi incerta, encara que és possible que els àngels cristians derivin de la representació de les victòries alades, I'origen de les quals es troba en les nikei gregues - divinitats femenines alades que baixen del cel per coronar els triomfadors de la batalla, vertaders missatgers divins alats - i que foren adoptades per la Roma Imperial. Serà a partir del segle $v$ quan aquesta imatge 
de I'àngel alat es consolidi, i arribarà fins als nostres dies de la manera següent: àngels que no són ni home ni dona, amb túniques blanques en comptes $d^{\prime}$ armadures, més pròpies dels guerrers amb què s'identificava els àngels als primers Ilibres de I'Antic Testament.

Jujol també dissenyarà el seu àngel, en aquest cas i com hem vist en planes anteriors, a partir de representacions tardomedievals: àngels alats vestits amb túniques, proveïts d'espasa i corona. La figura que Jujol construeix es presenta dempeus, suspesa sobre les dues cames i els talons dels peus calçats, fregant amb la punta dels dits la base en què recolzen. Les ales es troben desplegades; el braç dret, estès i subjectant una espasa Ilança per l'empunyadura que, en el seu extrem inferior, finalitza en creu de ganxo; el braç esquerre, semiencongit, subjecta amb la mà tancada I'escut. El vestuari consisteix en una senzilla túnica sense mànigues, elaborada amb planxa de coure que cobreix fins als peus, subjectada per un cinturó del mateix material que creua d'esquerra a dreta i de dalt a baix el tors, voltant la cintura. Una cinta al cap recull els flocs de cabell que cauen sobre el front i, finalment, la figura porta un barret corona rematat per una creu (fig. 15).

Tant la manera de vestir l'àngel com el posat no s'identifiquen de manera precisa amb les representacions que de l'àngel custodi es coneixen al Ilarg dels segles XV al XVIII, habitualment vestit amb una toga sense mànigues $i$, en lloc d'un escut a la mà esquerra, una corona, com a atribut propi del custodi. Potser la imatge de l'àngel custodi de Barcelona que coneixem del mestre Huguet és la que més elements de coincidència presenta, encara que ni la posició del braç dret ni el tipus de corona que mostra s'assemblen als realitzats per Jujol, que proveeix el seu àngel d'una mena de bací plegat coronat per una creu. Fins a quatre creus es troben a la figura, tres de les quals són utilitzades en els accessoris.

La primera, la trobem, com he assenyalat planes enrere, gravada sobre el tors de la figura; la segona, de tipus creu llatina, significa el punt més alt sobre el cap, damunt la corona; la tercera ocupa bona part de la zona anterior de l'escut que subjecta amb la mà esquerra, i la quarta i darrera creu defineix el final de l'empunyadura de l'espasa amb la forma denominada croysentea, ${ }^{42}$ amb la característica principal del retorn de les puntes en forma de doble ganxo. La representació de la creu, utilitzada a partir de diferents versions i present, amb l'única excepció de les ales, en tots els elements possibles de l'àngel suma, a la indiscutible voluntat de Jujol de personificar en l'àngel penell una identitat inequívocament evangelitzado$\mathrm{ra}_{1}{ }^{43}$ una especial afinitat per la combinació plàstica que suposa I'adaptació d'un mateix element, la creu, als diferents suports possibles - espasa, escut, corona i cos - que pertanyen a la mateixa figura. Igualment, al
42 «La creu heràldica és un senyal, o peça honorable, que ofereix nombroses variacions de forma. En francès és croiz en grafia medieval i crois en la moderna, en anglès cross i en castellà cruz. Els nostres heraldistes en diuen creu, llevat dels armorials de Salamanca i dels canonges de Barcelona de Tarafa, que usen la forma francesa croys», Martí DE RIQUER, Heràldica catalana, des de I'any 1150 al 1550, vol. 2, Barcelona, Quaderns Crema, 1983, p. 148, 385.

43 Jujol, sense fer ostentació de manera pública de les seves fortes conviccions religioses, sí que mantindrà, al llarg de la seva vida professional i acadèmica, una defensa constant, i transmesa de manera subliminal mitjançant els seus actes i comentaris, de la fe cristiana. Serveixi com a exemple el comentari recordat per I'arquitecte Raventós Farrarons, IIicenciat I'any 1917 i alumne de Jujol: «En cierta ocasión, mirándome la lámina me dijo: "Usted tiene la suerte de tener una T en el apellido; así, cada vez que firma puede poner una cruz, sin que nadie tenga que preguntarle el por qué" », Josep M. JuJo fill, op. cit., p. 125. 


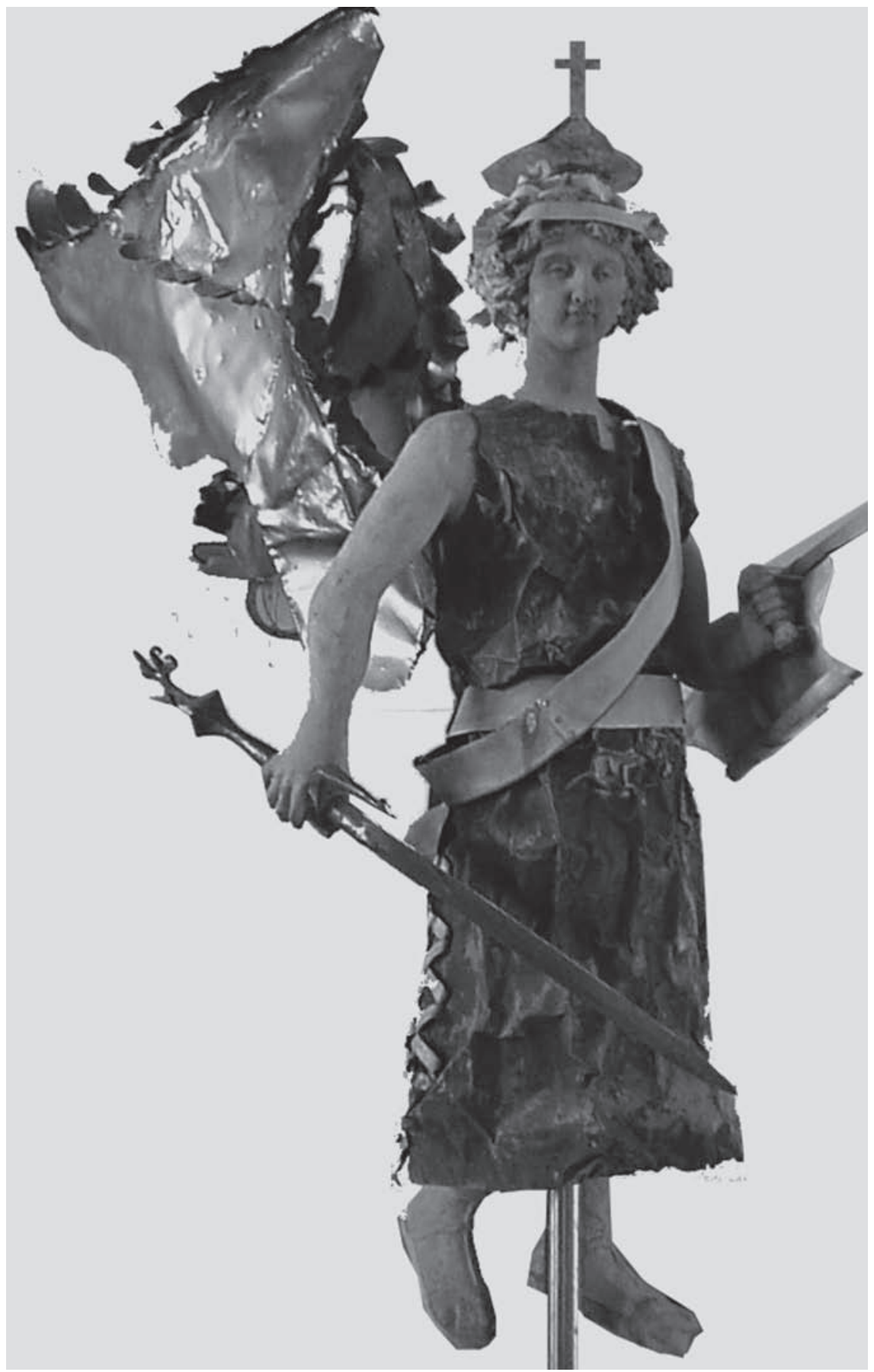

15. Àngel custodi. Resultat una vegada finalitzada la restauració. Fotografia cedida per Francesc Salvat. 
tractament barroc de vestidures, cabell i cintes que vesteixen l'àngel de múltiples plegaments i a un detallisme explícit en plomes amb rostre i cos d'adolescent, s'hi afegeix la clara intenció d'expressar la immaterialitat de l'àngel, manifestada en la posició dels peus que a penes toquen la base en què recolza. El cap lleugerament arquejat respecte del tors, el rostre mirant endavant, I'espasa en una actitud de tens repòs i les ales desplegades imprimeixen a la figura un tarannà d'atenció i vigilància amable sobre el municipi dels Pallaresos. Tant la dimensió antropomorfa com el moviment pertanyen a l'esfera dels éssers animats, eliminant així la barrera que separa una representació inerta d'una amb vida.

Som, doncs, davant un àngel que, en mans de Jujol, i encara que conserva alguna qualitat pròpia de l'estatuària del seu temps - eliminació de venes, musculatura al cos-, s'allunya dels elements més comuns - la vaporositat de les figures, els cabells que onegen, els rostres malenconiosos, els ulls entorxats, les formes foses que acaben per confondre's amb la pedra sobre la qual recolzen,$-{ }^{44}$ utilitzant els complements - vestit, espasa, escut - com a elements que singularitzen una determinada manera d'entendre I'humanisme escultòric. Una figura que, tant per les proporcions com per la inclusió d'elements propis d'un ser humà -el calçat-, s'humanitza i esdevé una figura celestial molt pròxima a una realitat terrenal que contempla des de les altures. I si el vent pertany a l'esfera d'allò natural i substancial en aquest camp, aquest vent haurà de ser, sens dubte, implícit en la figura que representa: xapes, cavalcades que recorden el cavalcament de les plomes i el moviment en contacte amb el vent, passamans metàl·lics que recorden cintes al vent, plecs de coure que identifiquen el moviment del vestit... Jujol hi incorpora així el moviment - característica essencial de les coses vives - i crea un vincle natural entre l'espectador i la seva obra.

\section{La resolució final de I'àngel: un assaig d'interpretació}

La idiosincràsia del món angèlic ha estat tractada per diversos autors que s'han capbussat dins les profundes aigües de I'angelologia, ja sigui des del pensament, l'art, la literatura o la crítica. De tots ells, és d'interès comentar-ne un que, per la condició de contemporani de Jujol i, especialment, per la influència manifesta en la vida artística catalana, permet d'establir algunes claus de lectura per interpretar l'àngel de Jujol inserit dins un marc més genèric: Eugeni d'Ors. ${ }^{45}$ Les seves afinitats artístiques amb el món clàssic i la voluntat d'establir una refundació de la cultura catalana,
44 Aquests trets diferenciadors farien referència, salvant la reducció de matisos, a autors com Manuel Fuxà, Josep Reynès, Agustí Querol, Miquel Blay, Llorenç Rosselló, Enric Clarasó, Eusebi Arnau, Josep Llimona, etc. Una classificació exhaustiva dels artistes mencionats, que I'autor divideix operativament en quatre generacions segons les característiques formals, es troba a J. M. Infiesta, Modernisme a Catalunya, Barcelona, Nou Art Thor, 1986, p. 12.

45 Fer esment aquí d'Eugeni d'Ors no és gratuït: Ia seva trajectòria com a crític i intellectual, consolidada amb les glosses, escrites durant setze anys a diversos mitjans de comunicació catalans, el situa com a defensor d'un canvi que catalitzarà amb els seus escrits. Adjectius com naturalisme, espontaneïtat, ruralisme, folklorisme i, per damunt de tot, individualisme seran posats en crisi per Eugeni d'Ors en favor d'una nova concepció social i col·lectiva de l'art. 
46 «[...] Compartia així els plantejaments d'Henri Bergson - a les classes del qual assistí - i del mateix James. També, en una certa mesura, de I'existencialisme, si bé només limitat al seu precursor, Søren Kierkegaard. I es trobava pròxim, sense que ens consti que n'obtingués un coneixement directe, a la fenomenologia d'Edmund Husserl. Amb tots aquests noms, però, no esgoto la llista ni de bon tros; com a símptoma revelador de la seva actitud amatent i oberta, ja a la primera dècada del segle s'assabentà de la psicoanàlisi freudiana. A més, s'interessava pels grans científics del moment. Així, doncs, en la mesura de les seves possibilitats, profundament determinades, no cal dir-ho, per I'endarreriment del seu entorn sociopolític, Ors compartí el periple dels intel-lectuals europeus», Mercè Rius, "Xènius, el fonament en falta», Literatura, segona època, 2006, p. 33.

47 Eugeni D'Ors, Introducción a la vida angélica, 1939, Madrid, Tecnos, 1986, p. 17. a costa de carregar contra els valors que a finals de segle privilegiaven els intel-lectuals del modernisme - recuperació dels oficis, de les tradicions i d'una història que afermava les bases d'una arquitectura nacional - , són conegudes a bastament. El contacte directe amb pensadors del moment, fora de les nostres fronteres i més enllà d'Europa, ${ }^{46}$ li atorgava un respecte, per sobre del seu entorn, difícil de contradir. És dins aquest marc on cal entendre la descripció següent de l'àngel custodi que realitza Xènius, de manera vehement i prenent com a referent la pintura que fa Pollaiuolo del caminar de Tobies amb sant Rafael; així descriu la fisonomia de I'àngel:

Magníficamente vigorosas, como un ave capaz de grandes vuelos, sus alas, nada tienen de morfologías mariposeras ni de esa pequeñez a lo "angelito» [...]. Alas, aquéllas, como las necesita para ser sostenido y volar en los aires un cuerpo gigantesco. Su amplitud, su fuerza, la tangible irrecusabilidad de una presencia física, que excluye todo lo fantasmal y vaporoso, todavía resaltan más, gracias al contraste con el aspecto del muchacho [...]. Cuantos contemplan el cuadro de Turín sienten enseguida la emoción de esta sublime paradoja: el débil mortal, cuyos enguantados pies apenas si se apoyan en el suelo - «forma que vuela»-, y cuyos cabellos rubios tocan un estilizado sombrerete, conducido por el Ángel moreno, al aire la corta crinera y - «forma que pesa»- pisando firme con los anchos pies, de cuya sandalia emerge, sin recato, el dedo pulgar más "real» que el hijo de la madre. ${ }^{47}$

D’Ors estableix una nova mirada a la casuística de la representació de I'àngel, a partir de l'observació de les figures que interpreten el text bíblic en el Llibre de Tobies, el viatge del fill de Tobies, representades per Pollaiuolo (fig. 16). L'àngel, paradigma d'allò eteri, personificació de I'aire i tan ràpid com lleuger, aquí és ara sòlid i pesant; en canvi, el noi a qui acompanya i custodia es torna fràgil i lleu. La contraposició entre ambdós personatges fa encara més agra la glossa amb què d'Ors argumenta la descripció a partir de la condició física dels protagonistes del llenç. La comparació amb l'àngel de la Casa Bofarull no és gratuïta; si obviem els trets més adolescents que té el rostre de la figura de Jujol, la resta del text d'Ors bé podria trobar-se en sintonia amb la resolució formal de I'àngel jujolià, acceptant I'intercanvi entre I'un i I'altre sense, per això, trair la imatge constitutiva. Els braços, les ales i, encara més, el cos de l'àngel de la Casa Bofarull responen a una complexitat adulta i musculada que poc té a veure amb els infantils àngels amb què se solia representar els missatgers del segle XVII. El símil entre I'àngel de Pollaiuolo, comentat per d'Ors, i el de Jujol obre una possibilitat amb referència als camins que I'art de I'arquitecte sembla anunciar: en ambdós es reconeix el sentit físic que comporta una presència que exerceix de guardià, la condició protectora 


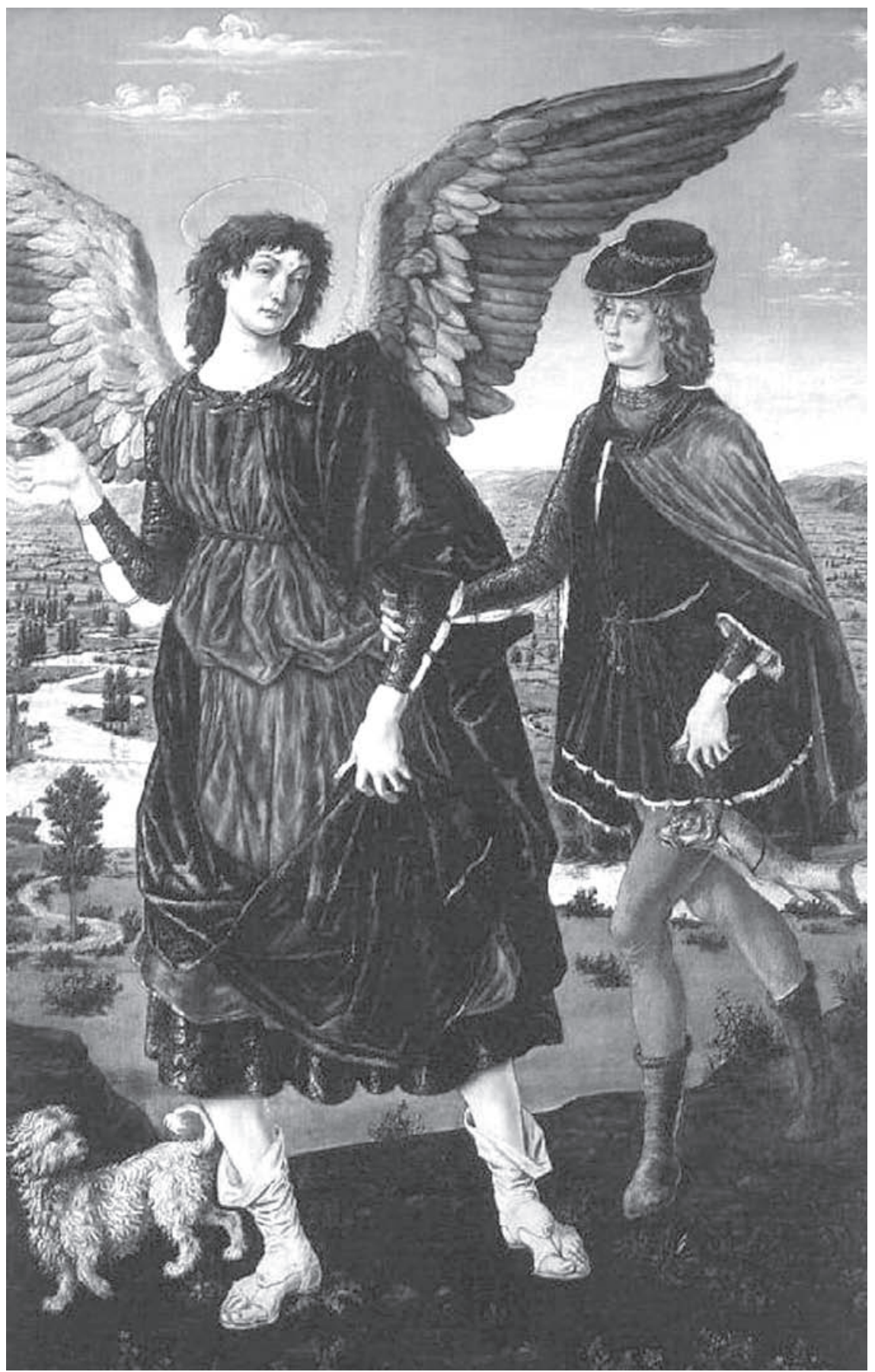

16. Representació de l'àngel custodi i Tobies, per Antonio de Pollaiuolo, cap a 1460. Torí, Galeria Sabauda. 
48 El mateix Ors ho explicitarà en una de les seves glosses: «Algú potser estranyi que Xènius escrigui avui aquestes coses, ell, que sempre, aquí i arreu, tant ha predicat, tant predica sobre l'acabament del Romanticisme, sobre el començ d'una Era clàssica nova i sobre altres coses semblants...- Però caldrà entendre's. Xènius mai ha parlat d'això del Classicisme, sinó com de concreció artística d'una cosa més vasta i fonamental, que és I'Humanisme. I si s'entusiasma amb la Renaixença i alaba el mateix segle XVIII, no és sols per lo que la literatura d'aquests temps deu a Horaci, sinó per lo que el seu viure deu a Rabelais i la seva ciència a Galileu i a Pico della Mirandola. L'entrada de I'art en Era clàssica suposa un mediterraneïsme general del viure», Eugeni D'ORS, "Horacionisme», Glosari (selecció), Josep Murgades (ed.), Barcelona, Edicions 62,1986, p. 48.

49 De nou les seves pròpies paraules són les que millor illustren el pensament d'Ors: "L'art comença a Grècia i no gaire més abans que Fidias. Decau en I'Edat Mitjana i torna a prendre empenta en el Renaixement. Tot està aquí. És la primera fórmula que havem après. ¿Per què canviarla?», Eugeni D'ORS, «En I'exposició d'art prehistòric», Glosari, op. cit., p. 332.

50 Sabem que el rostre s'executa a partir del motlle d'una noia amiga de la família Jujol, del qual exigeix, sens dubte, una concreció d'allò físic com a característica primera per protegir allò que habita la Terra. I com ha de definir l'estil aquesta suposada fisicitat, en termes de símbol i figura? Per a Eugeni d'Ors, aquesta reivindicació física de l'àngel neix de la voluntat de recuperar una universalitat d'allò clàssic com a solució a una modernitat no illustrada. ${ }^{48}$ Universal serà per a d'Ors equivalent a humanista, i clàssic, a I'art grecoromà. No existirà més origen ni millor referent. ${ }^{49}$

És també així com responen les formes de l'àngel de la Casa Bofarull? Recuperem el terreny d'allò concret repassant la figura, ara, des de la mateixa gènesi antropomorfa.

Els detalls de cadascuna de les parts del seu cos mostren una sensibilitat diferent, encara no tan allunyada de la descripció orsiana. Una cara femenina posarà rostre a l'ànge ${ }^{50}$ i sota el cos es mostra un tors més propi d'una dona que d'un home; fins aquí tot sembla normal; sembla que, una vegada més, i segons deien els cànons del darrer període del moment denominat modernisme, la figura s'identifica amb una dona, musa eternament present dels modelats suaus i evanescents que esculpiran autors com Llimona, Clarasó o Blay, o que faran palès pintors com Alexandre de Riquer. No obstant això, els detalls de la figura que construirà Jujol, vistos de prop (fig. 17), aparenten més les extremitats d’un jove fort i masculí que les d'una dona suau i evanescent. Els detalls que inclinen la balança cap a la masculinitat del model presentat es concreten en una gens dissimulada nou a la gola, uns braços vigorosos i sensiblement musculats i uns turmells i peus que recorden, en proporcions, I'àngel que dibuixa Pollaiuolo.

En definitiva, una figura allunyada dels cànons modernistes en voga $i$ que suggereix, d'altra banda, una aproximació al model orsià d'estatuària humanista emparada en la recuperació del classicisme i la vindicació d'allò mediterraneista. ${ }^{51}$ Des d'aquest punt de vista, la solució d'estàtua penell que dissenya i construeix Jujol es trobaria a mig camí, metàfora literal del periple que, en termes artístics, el modernisme anirà recorrent fins a ser substituït pel noucentisme, defès i introduït pacientment en la vida cultural catalana per Eugeni d'Ors.

Però si la possibilitat d'aquest paral-lelisme conceptual entre ambdós autors no deixa de sustentar-se sobre la sempre fràgil línia d'afinitats formals que adjudica a determinats corrents l'obra d'aquells autors que se situa a cavall entre una tendència artística i una altra, no podem deixar d'interrogar-nos sobre l'ús d'aquestes peces en referència a un programa més general que validi la inclusió de la figura en un moviment o en un altre. Si la reivindicació de I'àngel físic d'Eugeni d'Ors neix de la vinculació a la cultura humanista 0 , verbalitzat en termes més geogràficament locals, de la voluntat d'incorporació dels intel-lectuals catalans a les tas- 

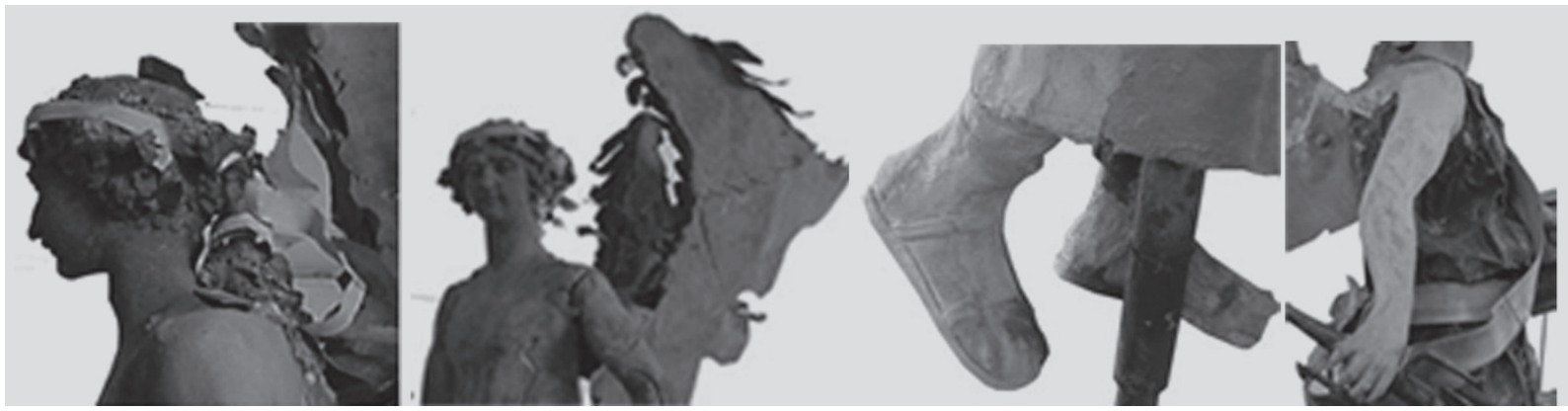

17. Detalls diversos de l'àngel custodi. D'esquerra a dreta, coll, tors, peus i braç. Fotografies cedides per Francesc Salvat.

ques de construcció d'un nou concepte de ciutat - un nou concepte de Barcelona, lluny encara de I'atracció cosmopolita exercida per ciutats com Viena o París-, en Jujol, aquesta mateixa modernitat, situada d'esquena als suggeriments que arriben de més enllà dels Pirineus - encara que mirant igualment en direcció obliqua a la proposta orsiana-, utilitzarà el referent històric com a punt de partença per elaborar, mitjançant una transformació no tan intel·lectual com material, una resposta que representa un punt igualment distant d'ambdues actituds: la crítica a un projecte intellectual absolutament allunyat dels sentiments rituals i arcaics dels nuclis rurals i la negació d'unes formes que ja no transmeten el fenomen centrífug i insolidari de la individualitat de l'artista proposada per un modernisme que s'acaba.

L'àngel que Jujol emplaça al punt més alt de la Casa Bofarull cerca, mitjançant els materials, les dimensions, l'execució i la voluntat de fer partícips els habitants dels Pallaresos, la compenetració entre Terra i cel, entre tradició i moral, entre necessitat i resposta a través d'una força plàstica que no pot sinó ser admirada des del sòl, des del territori. El relat de la col·locació de I'àngel sobre el mirador, en paraules del fill de I'arquitecte, sintetitza l'exposat:

Una vez retirados los andamios tras la colocación del ángel, y con la llegada del anochecer, por iniciativa del autor del proyecto se prendió fuego a los dos fogariles del mirador. El cielo, todavía azulado, iba volviéndose oscuro mientras el vestido del ángel brillaba junto a sus alas que se movían suavemente con el paso del aire; semejaba una aparición celestial entre fuegos suspendidos en el vacío milagrosamente. Jujol, entusiasmado como un niño, lo contemplaba desde la era. ${ }^{52}$

No cal anar gaire lluny per trobar, en termes similars, una narració que ajusti I'argument a l'efecte plàstic derivat de la contemplació de I'àn- de qui I'arquitecte dirà que té cara d'estàtua. Josep M. JuJOL fill, op. cit., p. 90.

51 «Classicisme» $i$ «mediterraneista» respondran a la reducció de I'híbrid format per les múltiples versions que cada artista farà del model italià, mesclat amb les necessàries dosis de rusticitat com a component necessari per fer possible que sigui adoptat pel nou programa del projecte de la burgesia urbana catalana.

52 Josep M. JuJoL fill, op. cit., p. 90. 
53 Èxode 3:1-5.

54 Filó d'AlexAndria: «Teofanía en la zarza ardiente», Obras completas, Madrid, Trotta, 2009, p. 41. gel. Recordem la descripció recollida a l'Èxode sobre la visió de l'esbarzer que cremava sense consumir-se:

Moisès pasturava les ovelles de Jetró, el seu sogre, sacerdot de Madian. Tot menant el ramat més enllà del desert, arribà a la muntanya de Déu, I'Horeb. I I'Àngel de Jahvè se li va aparèixer sota la forma d'una flama roent, que sortia del mig d'un esbarzer. Ell mirà: I'esbarzer cremava, roent, i tanmateix no es consumia. Aleshores Moisès es digué: Aniré a veure aquest estrany espectacle: què ho fa que l'esbarzer no es cremi. Jahvè va veure que s'acostava per mirar, per això del mig de l'esbarzer Déu el cridà: Moisès!, Moisès! Aquí em tens, respongué. I digué: No t'acostis pas aquí! Treu-te les sandàlies dels peus, perquè el lloc que trepitges és terra santa. ${ }^{53}$

Una versió més lliure i desenvolupada, la trobem en Filó d’Alexandria:

Cuando una vez lleva el rebaño a un lugar bien provisto de agua y pastura, donde crecía mucha vegetación apta para las ovejas, contempla una visión fascinante al acercarse a un bosquecillo. Había allí una zarza, especie vegetal espinosa y en extremo débil, que arde de repente sin que fuego alguno la alcance; tomada toda ella desde las raíces hasta sus ramas por una inmensa llamarada, permanecía sin mengua como si tuviera una fuente inagotable. No se consumía, como una sustancia impasible que no fuera materia del fuego, sino que del fuego se alimentara. En medio de la llama había una figura de extrema belleza, sin ningún parecido con las cosas visibles, imagen del más divino aspecto, luz refulgente con mayor claridad que el fuego. Podría presumirse que era imagen del Existente, pero llamémoslo Ángel, pues con seguridad anunciaba las cosas que habrían de acontecer mediante la visión más imponente, en un silencio más elocuente que la voz. La zarza ardiente es símbolo de los que padecen injusticia; la llama de fuego, de los que la cometen. El hecho de no consumirse lo que ardía es símbolo de que los que padecen injusticia no serán destruidos por sus agresores, sino que para éstos el ataque quedará ineficaz e inútil, y para aquéllos la confabulación no tendrá consecuencias. El ángel es símbolo de la providencia que Dios tiene, que en gran silencio alivia los temores según las esperanzas de todos. ${ }^{54}$

L'estil més literari de Filó recull I'escena de l'èxode que transmet, de manera magistral, I'efecte que, en paraules de Jujol fill, descriu I'embadocament del seu pare davant la visió de l'àngel penell sobre les flames que brollen de les teieres, al mirador de la Casa Bofarull (fig. 18). No és difícil imaginar que, a l'admiració per la suggestió de la visió del foc sota la llum del capvespre, quan encara aquesta permet distingir veladament els cossos situats a certa distància però sense obtenir una definició nítida i clara, s'afegirà la imatge bíblica que, amb gran probabilitat, es trobarà resident 


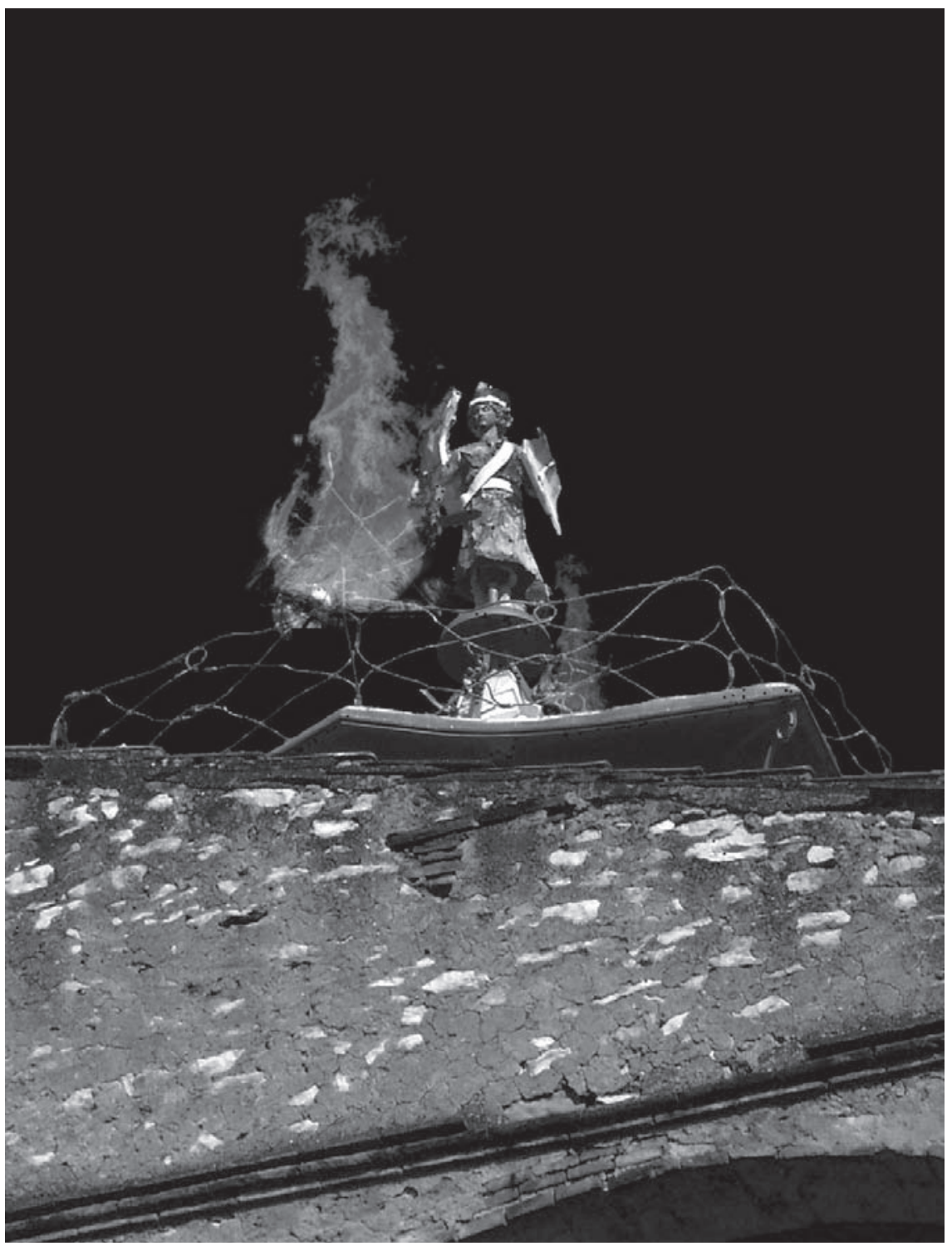

18. Simulació de la visió nocturna de l'àngel custodi de la Casa Bofarull, amb les teieres en flames. Així devia veure Josep M. Jujol la coronació de la casa quan en va finalitzar la col-locació. Imatge: elaboració de l'autor.

a la ment de I'arquitecte i que legitimarà l'opció plàstica a ulls de la població dels Pallaresos.

Signe, manifestació espiritual, però també, no ho oblidem, element útil que assenyala una de les variables més influents al treball dels homes i les 
dones del camp: el vent. Estàtua i penell, àngel i custodi, el muntatge es du a terme durant el mes de desembre de 1918, quan ja han estat projectats, encara que no construïts, els edificis annexos que acompanyaran el recorregut de qui vulgui trucar a la porta principal de la casa de les germanes Bofarull.

\author{
Guillem Carabí \\ Universitat Internacional de Catalunya \\ carabi@uic.es
}

L'Àngel PENELL QUE CORONA LA CASA BOFARULL: ALgUnes CONSIDERACIONS A L'ENTORN DE L'ESCULTURA

Tant si el viatger hi arriba des del nord com des del sud, la primera imatge que s'obté del nucli urbà dels Pallaresos és la visió de l'agulla del campanar de l'església, seguida, a la mateixa alçada, pel perfil de I'àngel penell que corona la Casa Bofarull. Es tracta d'una imatge poc o gens habitual en el paisatge rural, on l'agulla dels campanars sempre ha assenyalat la major i única alçada que sobresurt per damunt de les cases. L'article té com a objectiu analitzar la singular peça que corona la casa, obra de I'arquitecte Josep M. Jujol, com a part del programa iconogràfic d'una reforma que no desatén les relacions que contreu amb el territori, amb l'ús de la figura o amb la seva imatge. L'anàlisi iconogràfica, tècnica, perceptiva i formal ens permetrà apropar-nos, a través de l'àngel penell, als processos creatius del seu autor, situat cronològicament a la darreria del modernisme, però les solucions del qual escaparan de les convencions del moment.

Paraules clau: àngel, Pallaresos, Bofarull, Jujol, penell.

The angel-shaped weather vane that tops the Bofarull House: considerations about the SCULPTURE

Whether the traveller arrives from the north or the south, the first sight of the town of Els Pallaresos is the church steeple, followed, at the same height, by the profile of the angel-shaped weather vane that crowns the Bofarull House. This is an unusual image in the countryside, where church spires were always the highest structures protruding above the houses. The article aims to dissect the singular piece that crowns the house, designed by architect Josep M. Jujol, as part of the iconographic program of reform that does not neglect its relationship with the land, with the use of the figure, or with its image. The iconographic, technical, perceptual and formal analysis will allow us to understand, through the angel-shaped weather vane, the creative processes of its author, chronologically situated at the end of the Modernisme movement, but whose solutions escape the conventions of the time.

Keywords: angel, Pallaresos, Bofarull, Jujol, weather vane. 